Florida International University FIU Digital Commons

FIU Electronic Theses and Dissertations

University Graduate School

$12-4-2000$

\title{
In vitro effect of shark cartilage on human leukocyte function
}

Aline Cornelissen

Florida International University

DOI: $10.25148 /$ etd.FI14061516

Follow this and additional works at: https://digitalcommons.fiu.edu/etd

Part of the Laboratory and Basic Science Research Commons

\section{Recommended Citation}

Cornelissen, Aline, "In vitro effect of shark cartilage on human leukocyte function" (2000). FIU Electronic Theses and Dissertations. 2515.

https://digitalcommons.fiu.edu/etd/2515

This work is brought to you for free and open access by the University Graduate School at FIU Digital Commons. It has been accepted for inclusion in FIU Electronic Theses and Dissertations by an authorized administrator of FIU Digital Commons. For more information, please contact dcc@fiu.edu. 
FLORIDA INTERNATIONAL UNIVERSITY

Miami, Florida

IN VITRO EFFECT OF SHARK CARTILAGE

ON HUMAN LEUKOCYTE FUNCTION

A thesis submitted in partial fulfillment of the

requirements of the degree of

MASTER OF SCIENCE

in

MEDICAL LABORATORY SCIENCES

by

Aline Cornelissen

2001 
To: Dean Ronald Berkman

College of Health and Urban Affairs

This thesis, written by Aline Cornelissen and entitled In Vitro Effect of Shark Cartilage on Human Leukocyte Function, having been approved in respect to style and intellectual content, is referred to you for judgment.

We have read this thesis and recommend that it be approved.

Steven D. Obenauf

Janet A. Lineback

Sylvia L. Smith, Major Professor

Date of Defense: December 4, 2000

This thesis of Aline Cornelissen is approved.

Dean Ronald Berkman College of Health and Urban Affairs

Interim Dean Samuel S. Shapiro Division of Graduate Studies

Florida International University, 2001 
(C) COPYRIGHT 2001 by Aline Cornelissen

All rights reserved. 


\section{DEDICATION}

I dedicate this thesis to my family. To my parents and sisters whose support and admiration brought me here today, and to my husband and daughter, who fill my life with joy and desire to reach further. 


\section{ACKNOWLEDGMENTS}

I would like to thank my mentor, Dr. Sylvia L. Smith for her guidance, great encouragement and inspiration, and also for receiving me in her laboratory, providing the great opportunity to pursue the present work. I also wish to thank the members of my committee, Dr. Steven Obenauf and Dr. Janet A. Lineback, for their valuable suggestions and patience. I am especially thankful for all the people who kindly donated blood to be used for this project. I want to express my gratitude to my husband, Erik Cornelissen, for helping me to edit this thesis.

I acknowledge my colleagues, whose cooperation and encouragement were fundamental for completion of this research project, Karlene Noicely, Nichole Hinds, Betzabel Gonzalez, Jeanette Builes, Eric Zeledon and Barbara Webb. 


\section{ABSTRACT OF THE THESIS \\ IN VITRO EFFECT OF SHARK CARTILAGE \\ ON HUMAN LEUKOCYTE FUNCTION}

by

Aline Cornelissen

Florida International University, 2001

Miami, Florida

Professor Sylvia L. Smith, Major Professor

Previous in vitro studies have shown that shark cartilage extracts stimulate human leukocytes to release significant levels of TNF $\alpha$, a cytokine typical of a Th1 immune response. The purpose of this study was to investigate further the effects of shark cartilage on cellular immune function, particularly cell proliferation, apoptosis, and IL-4 and INF $\gamma$ production. The viability and proliferation of cell cultures grown in the presence of shark cartilage extract was not significantly different from unstimulated control cultures or those stimulated with mitogens (Con A, PMA, LPS), respectively. The effect of shark cartilage on apoptosis was determined by microscopic analysis of morphological apoptotic changes and by the detection of DNA fragmentation observed as characteristic ladder formation in agarose gel electrophoresis. While DNA fragmentation could not be demonstrated for cartilage-stimulated cells, characteristic morphological changes, indicative of apoptosis, were observed in leukocytes following incubation with shark cartilage extract. A statistically significant difference was not noted in the number of apoptotic cells present in cartilage-stimulated leukocytes and those stimulated with 0.5 
$\mu \mathrm{M} / \mathrm{ml}$ of staurosporine, suggesting that apoptosis is induced in the presence of cartilage extract. Culture supernatants of cartilage-stimulated leukocytes were assayed for IL-4 and IFN- $\gamma$ by enzyme-linked immunosorbent assay (ELISA). Although a low level of IL-4 and INF $\gamma$ was detected in culture supernatants of Con A and PMA stimulated cells it was not significantly different from that of unstimulated control cultures. Thus the significance of the absence of detectable IL-4 or INF $\gamma$ in supernatants of cartilagestimulated cultures could not be determined. However, as previously shown, supernatants did contain TNF $\alpha$. Results of the study did not show a definitive pattern of cytokine production, characteristic of either a Th1 or Th2 type immune response. 


\section{TABLE OF CONTENTS}

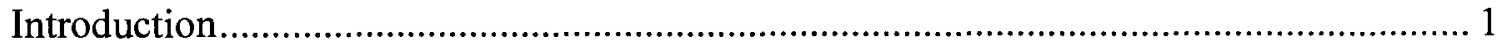

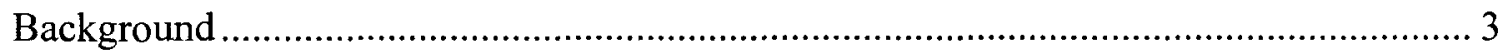

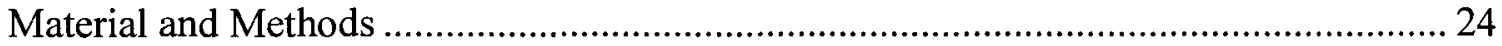

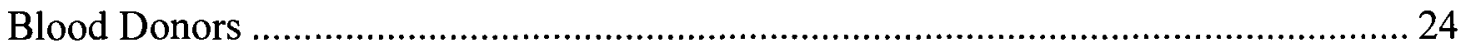

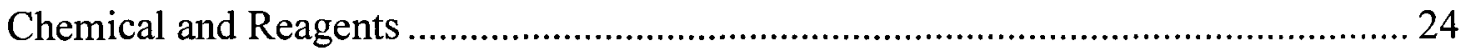

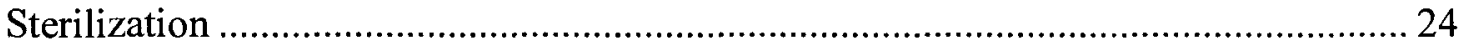

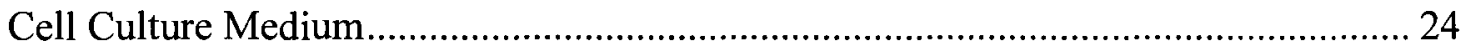

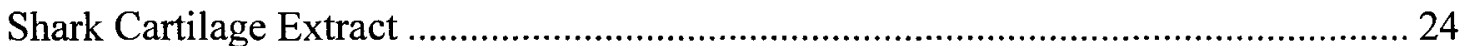

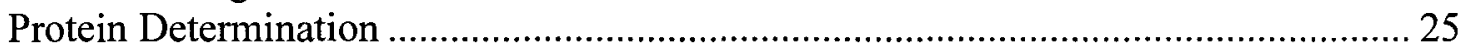

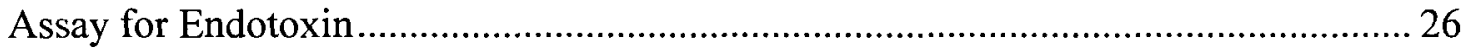

Isolation of Human Peripheral Blood Leukocytes ...................................................... 28

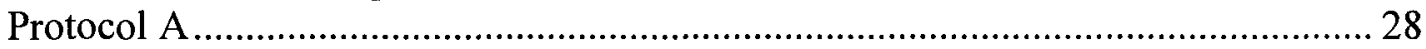

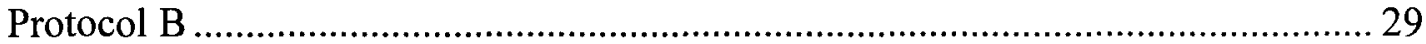

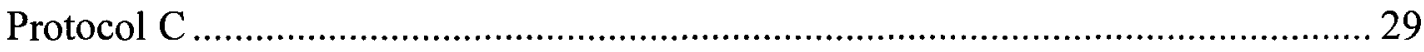

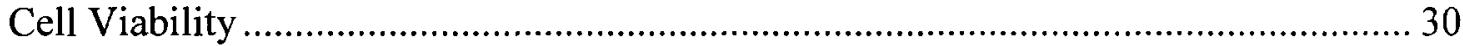

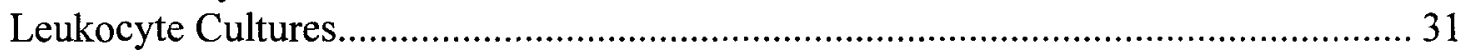

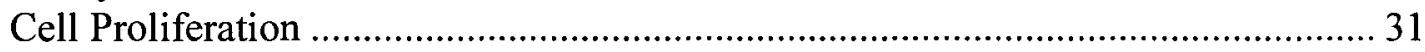

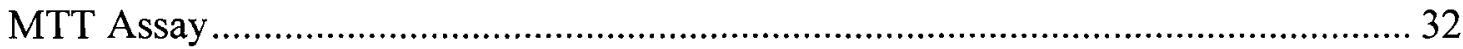

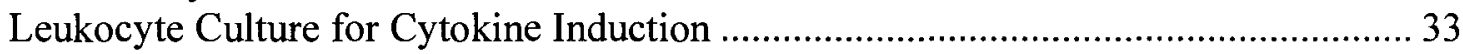

Leukocyte Culture for Assessment of Apoptosis ..................................................... 34

Preparation of Leukocyte Cytospin monolayers ..................................................... 35

Assay for Extracellular Cytokine in Stimulated Cell Cultures ..................................... 37

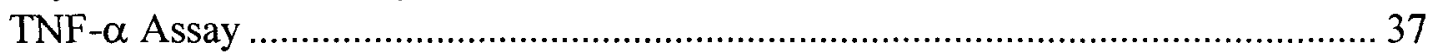

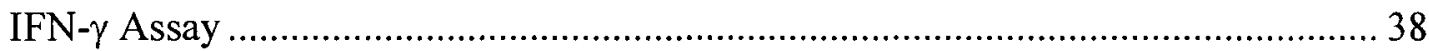

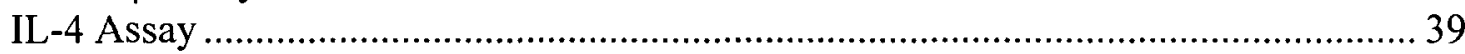

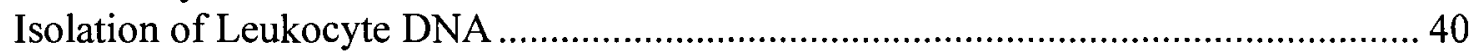

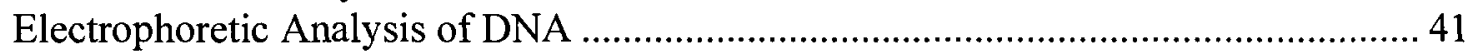

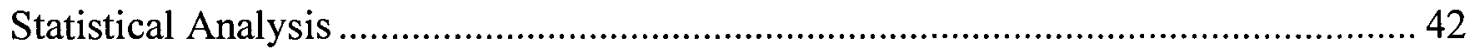

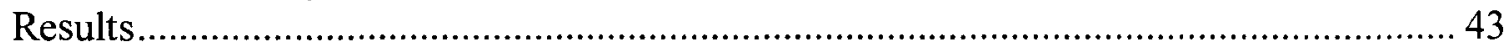

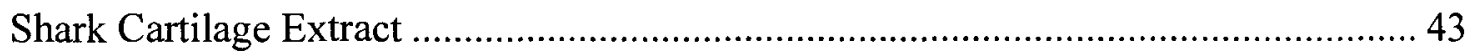

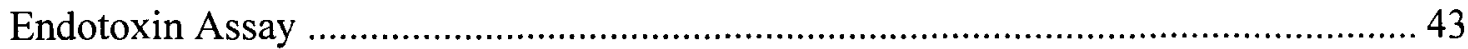

Comparison of Cell Separation Methods ............................................................ 45

Viability and Proliferation of Leukocyte in culture ................................................... 46

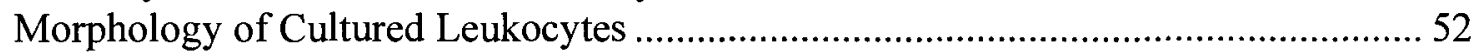

Effect of Shark Cartilage on in vitro Leukocyte Proliferation ................................... 52

TNF- $\alpha$ Secretion by Shark Cartilage-Stimulated Leukocytes ..................................... 56

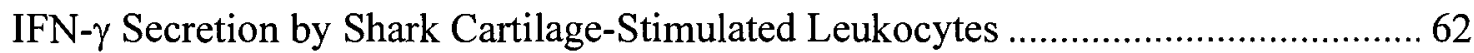

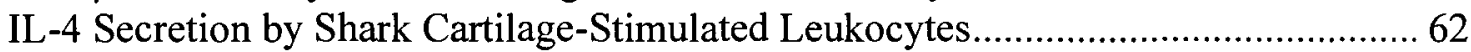

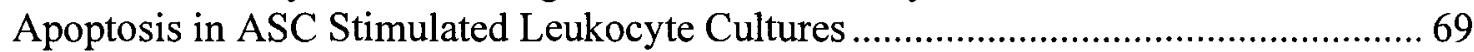

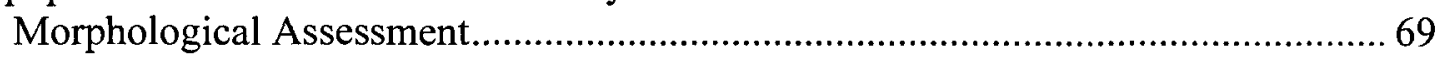

Assessment by DNA Fragmentation Pattern ...................................................... 73 


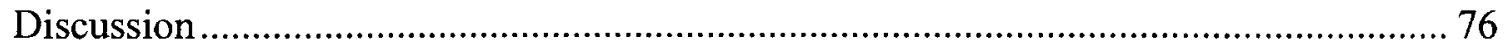

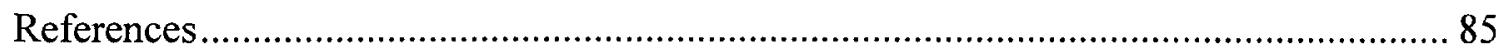

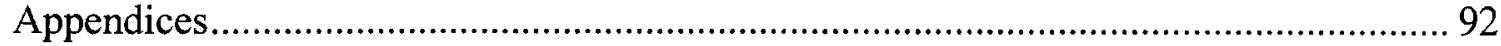


1. Endotoxin assay.

2. Analysis of leukocyte fractions.

3. In vitro cell proliferation.

4. Cell proliferatin measured by MTT assay 56

5. Production of TNF- $\alpha$ by PBL cultures. 59

6. Production of TNF- $\alpha$ by PBMC cultures. 60

7. Apoptotic cells in PBL cultures. .71

8. Apoptotic cells in PBMC cultures. 74 


\section{LIST OF FIGURES}

FIGURE

PAGE

1. Summarized flow chart of the experimental approach....

2. Cells undergoing apoptotic changes........................................ 36

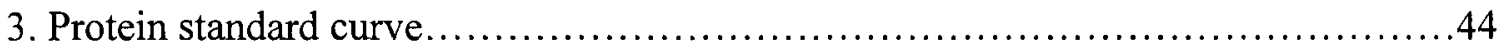

4. Human leukocyte isolated from whole blood..................................47

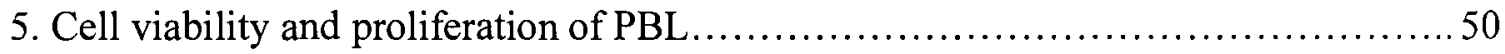

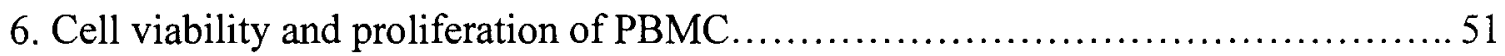

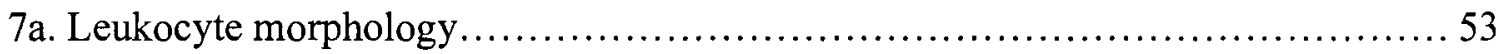

7b. Leukocyte morphology ................................................... 54

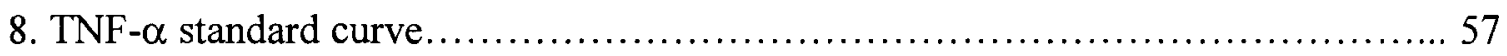

9. Production of TNF- $\alpha$ by PBL cultures........................................ 60

10. Production of TNF- $\alpha$ by PBMC cultures..................................... 61

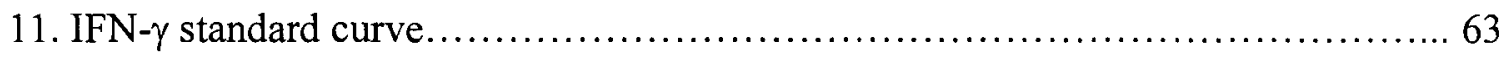

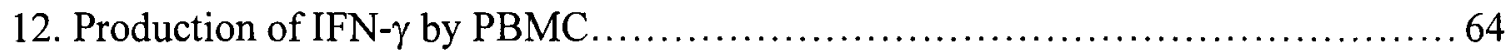

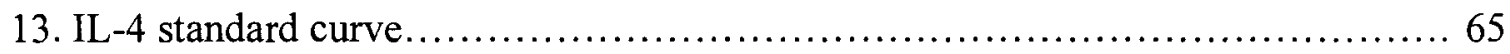

14. Production of IL-4 by PBMC cultures.................................. 66

15. IL-4 standard curve ................................................... 67

16. Production of IL-4 by PBMC cultures................................ 68

17. Cytospin monolayers of PBL cultures...................................... 71

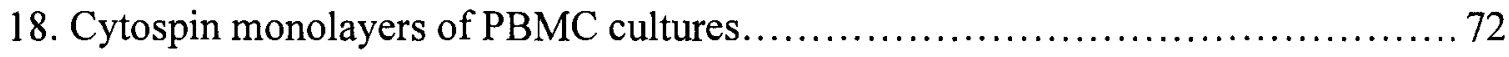

19. DNA fragmentation analysis.......................................... 75 


\section{Introduction}

Shark cartilage therapy has been widely used for the treatment of a variety of chronic diseases. It is used as an anti-inflammatory agent, in wound healing and also for prophylactic purposes. During a conference sponsored by the National Institutes of Health $(\mathrm{NIH})$ on alternative therapies in 1992 , researchers reported that about 50,000 Americans were using shark cartilage and that these numbers were expected to increase through the following years (Workshop on Alternative Medicine. Washington, DC: US Government Printing Office; 1992). However, there is no direct evidence that shark cartilage offers any benefit in the treatment of human diseases or as a prophylactic agent. An earlier study carried out in our laboratory showed that an acid extract of shark cartilage, prepared from a commercial source of cartilage, stimulated human leukocytes to release significant levels of TNF- $\alpha$. TNF- $\alpha$ is a cytokine characteristic of a Th-1 response, which represents an inflammatory response. It is not known what other cytokines are induced by shark cartilage and whether the cellular response is associated with the activation of any particular cell type or the production of particular cytokines. IL-4 plays an important biological role in cell-cell communucation as it modulates cytokine production by many cells of the immune system. Unlike TNF- $\alpha$, IL- 4 is a cytokine that typically induces in vivo a Th-2 response, i.e. an anti-inflammatory response.

The purpose of this study is to further investigate the effects of shark cartilage on cellular immune function. The proposed research will primarily focus on the secretion of IL-4 and IFN- $\gamma$ by shark cartilage-stimulated human leukocytes and will also examine in 
vitro the effect of shark cartilage on apoptosis, proliferation and viability of human leukocytes. Human leukocytes and a peripheral blood mononuclear cell-enriched fraction of leukocytes will be cultured in the presence of shark cartilage, and culture supernatants will be assayed for IL-4, IFN- $\gamma$ and TNF- $\alpha$, which will be detected by enzyme-linked immunosorbent assay (ELISA). The assessment of apoptosis will be made through analysis of morphological apoptotic changes observed by light microscopy, and by the detection of DNA fragmentation with characteristic ladder formation in agarose gel electrophoresis. Proliferation will be measured by the MTT assay and by manual cell count. 


\section{Background}

During the last decade, as an alternative to conventional medicine, scientists have been searching for new effective methods for the treatment and prevention of diseases, such as cancer, AIDS, autoimmune diseases and other chronic, degenerative diseases. Alternative Medicine, also referred to as Complementary Medicine, is defined by Eisenberg et al. (1993) as treatments and health care practices not taught widely in medical schools, not generally used in hospitals, and not usually reimbursed by medical insurance companies. This definition is now not appropriate, since many alternative remedies have recently found their way into the medical mainstream. Medical schools teach alternative medicine, hospitals and health maintenance organizations offer it, and laws in some states require health plans to cover it. A more state-of-the-art definition is the diagnosis, treatment and/or prevention, which complements mainstream medicine by contributing to a common whole, by satisfying a demand not met by traditional medicine or by diversifying the conceptual framework of medicine (Angell \& Kassirer, 1998). The National Center for Complementary and Alternative Medicine (NCCAM) of the National Institutes of Health $(\mathrm{NIH})$ has grouped the practice of alternative medicine into the following five major domains: (1) alternative medical systems (traditional oriental medicine including acupuncture, herbal medicine and oriental massage; ayurvedic medicine that is India's traditional system of medicine and includes diet, exercise, meditation, herbs, massage, exposure to sunlight and controlled breathing; homeopathy and naturopathy), (2) mind-body interventions (meditation, hypnosis, dance, music and art therapy, prayer and mental healing), (3) biological-based therapies (herbal, special 
dietary, orthomolecular, and individual biological therapies including use of shark cartilage), (4) manipulative and body-based methods (chiropractors, osteopathic manipulation and massage therapists), and (5) energy therapies (biofield therapies and bioelectromagnetic-based therapies) (http://nccam.nih.gov/nccam/fcp/classify/) (appendix i).

The practice of alternative medicine has gained popularity among patients and the general population. The annual prevalence of Complementary and Alternative Medicine (CAM) use in the U.S.A is $40 \%$, in Australia 50\% and in Germany $65 \%$ (Ernst and Cassileth, 1999). Many factors may be driving this popularity, such as a rise in chronic diseases, greater access to health information, increased demand for improved quality of life, and the desire for more effective and less toxic therapies (Marcus et al., 1999). In 1992, Congress established within the NIH an Office of Alternative Medicine with the purpose of evaluating the efficacy and safety of alternative remedies. More recently, in 1998, the Congress elevated the NIH Office of Alternative Medicine to the National Center for Complementary and Alternative Medicine (NCCAM) at the NIH. In 1999, the Center had a budget of $\$ 50$ million, which was increased in 2000 to $\$ 68.7$ million. The reason for Congress's growing interest in CAM is the estimated 83 million adults who used at least one form of alternative medical therapy in 1997, compared with 60 million adults in 1990 (Eisenberg et al., 1998). There is a great demand by the public and scientific community that CAM studies be carried out, which provide scientifically reliable evidence of safety and efficacy following rigorous testing, similar to that required by the Food and Drug Administration (FDA). That is, they must be subjected to the same level of scrutiny required for the approval of drugs and that result of studies be published 
in reputable peer-reviewed journals. The latter is a mission of the newly created NCCAM (Muscat, 1999). An increasing number of publications in scientific journals are devoted to alternative medicine, particularly in the area of cancer research, where there are a large number of studies involving CAM, probably because of the widespread use of alternative regimens by cancer patients. (Ernst and Cassileth, 1999) Unfortunately, such therapies can prove harmful in some patients by delaying needed mainstream treatment, or cause undesirable physiological problems if they have unexpected effects on the recipient.

One form of CAM, which is gaining considerable popularity is the oral use of shark cartilage, not only as a therapeutic agent, particularly in case of cancer, but also as a prophylactic measure. The interest in shark cartilage stemmed from early studies carried out by Folkman (1971). Initial interest in cartilage as an inhibitor of angiogenesis came from its unique physical characteristic of being a tissue lacking nerves or blood vessels. The absence of blood vessels prompted several researchers to investigate cartilage as a possible source of inhibitors of angiogenesis (Langer et al., 1976). The rationale being that by limiting or inhibiting blood vessels to developing tumors their growth and/or survival could be controlled. Studies have found that cartilage contains more naturally occurring factors that inhibit angiogenesis than molecules that activate angiogenesis, which may well account for the absence of blood vessels in cartilage (Langer et al., 1976).

During the early seventies, Folkman (1971) originally proposed that solid tumors could not grow beyond the size of 1-2 mm without inducing the formation of new blood vessels to supply the nutritional needs of the tumor, and he suggested that this neovascularization might be a novel target for cancer therapy. The development of a new 
vascular network from a pre-existing vessel is called angiogenesis and occurs in physiological states such as embryonic development, menstrual cycle and wound healing, where it is necessary to continuously supply the tissue with oxygen and nutrients as well as for removal of waste products. However, excessive angiogenesis is part of the pathology of several non-related diseases. Among these diseases are cancer, atherosclerosis, rheumatoid arthritis, psoriasis, endometriosis and diabetic retinopathy (Griffioen and Molema, 2000). In case of cancer, tumor cells secrete angiogenic proteins, such as vascular endothelial growth factor (VEGF), which binds to specific receptor on the endothelial cells lining the blood vessels (Griffioen et al., 1998). When these cells are activated by angiogenic signals, the process of forming a new blood vessel is initiated with the production of enzymes called matrix metalloproteinases (MMPs). MMPs create an opening in the blood vessel wall and break down the surrounding tissue to clear a path for endothelial cells to move toward the source of the angiogenic signals. The endothelial cells then divide and eventually strands of new endothelial cells organize into hollow tubes creating a new network of blood vessels, thereby, connecting the tumor to a network of existing blood vessels (Griffioen et al., 1998). Based on these observations, investigators believed that the inhibition of angiogenesis might offer a new and powerful approach to cancer treatment, either alone or in combination with conventional therapies. This approach may also benefit other chronic diseases where undesirable angiogenesis is involved. In the case of chronic inflammatory diseases, including rheumatoid arthritis and psoriasis, neovascularization is a proeminent feature. Angiogenesis is believed to be required for the pannus formation, which is the characteristic change in the synovial architecture in rheumatoid arthritis and psoriasis (Jackson et al., 1997; Storgard et al., 
1999). This neovascularization not only maintains the chronic architectural changes via delivery of required blood-borne elements to the pannus, but also to play an active role in the inflammation by being a source of inflammatory cytokines, chemokines, and proteases. Many cell types are capable of producing angiogenic factors when their enviroment becomes inflammatory, such as tumor cells, keratinocytes, corneal fibroblasts, synovial fibroblasts, monocytes and macrophages. Monocytes and macrophages can be found at most sites where angiogenesis is occurring in abnormal enviroment and they can produce almost every growth factor and cytokine known to regulate angiogenesis (Jackson et al., 1997). Currently, investigators are using four strategies to design anti-angiogenesis agents: 1) block the MMPs, 2) directly inhibit normal endothelial cell proliferation, 3) block factors that stimulate angiogenesis, and 4) block the action of integrin, a molecule on the endothelial cell surface that binds the endothelial cell with the extracellular matrix (Griffioen and Molema, 2000).

Brem and Folkman (1975) were the first to demonstrate the antiangiogenesis property of mammalian cartilage on tumor development. When cartilage obtained from neonatal rabbits was implanted with V2 carcinoma cells into rabbit cornea or the chorioallantoic membrane of chick embryo, tumor inhibition was noted. Based on these results, Lee and Langer (1983) undertook search for this vascular inhibitor in sharks, which unlike mammals, have an endoskeleton composed entirely of cartilage that represents approximately $6 \%$ of their total body weight. Shark cartilage extract was incorporated into polymer pellets and implanted into the cornea of New Zealand white rabbits, together with V2 carcinoma tumors. They found that a crude extract of shark cartilage prepared by extraction with a solution containing $1 \mathrm{M}$ guanidine and $0.02 \mathrm{M} 2$ - 
(N-morpholino) ethanesulfonic acid (MES) for 41 days at room temperature strongly inhibited tumor neovascularization and that the inhibitor did not appear to act directly on the tumor itself, but rather on capillary advancement towards the tumor. Subsequently, Prudden (1985) reported on clinical cases in which patients were treated with a specific preparation of bovine cartilage called Catrix. Thirty one cancer patients showed a high response rate of $90 \%$ over extended periods of treatment. Prudden suggested that Catrix has the capacity to arrest the growth of many types of tumors, but not to eliminate them completely. Several investigators further studied the antitumor activity and immunoregulatory effects of Catrix (Romano et al., 1985; Durie et al., 1985; Rosen et al., 1988). Generally, they found that Catrix has antitumor activity demonstrating inhibition of tumor growth, and an immunostimulatory activity with enhancement of antibody response. The substance in Catrix that induces the immunomodulatory effects appeared to be related to chondroitin sulfate, based on similar effects observed in vivo with that shown previously with chondroitin sulfates $\mathrm{C}$ and $\mathrm{A}$ and also the sensitivity of Catrix to digestion with chondroitinase $\mathrm{ABC}$, an enzyme with specificity for chondroitin sulfates and related glycosaminoglycans.

Moses et al. (1990) were the first to isolate a protein derived from bovine cartilage that inhibited angiogenesis in vivo, and capillary endothelial cell proliferation and migration in vitro. They also found that the angiogenesis inhibitor is also a collagenase inhibitor. Since these earlier studies, other investigators have demonstrated the antiangiogenic activity of shark cartilage, and have isolated the antiangiogenesis component from shark cartilage (Oikawa et al., 1990; Sheu et al., 1998). Oikawa et al. (1990) conducted a study to evaluate the inhibitory activities of crude fractions of 
Japanese shark cartilage. They analyzed the angiogenic response of rabbit cornea following implantation of rabbit VX-2 carcinoma, and embryonic angiogenesis in chick embryo chorioallantoic membranes (CAM) in the presence and absence of shark cartilage fractions. They demonstrated inhibitory activities of crude fractions in the two assays performed, mainly with fractions of molecular weight between 1,000 and 10,000 Daltons, and that this inhibitory activity was resistant to heat treatment ( 2 hours at $37^{\circ} \mathrm{C}$ or 3 minutes at $100^{\circ} \mathrm{C}$ ). More recently, a potent angiogenesis inhibitor, U-995, was purified from blue shark cartilage (Sheu et al., 1998). The study found that U-995 is composed of two single peptides with molecular mass of 10 and $14 \mathrm{kDa}$, which inhibit endothelial cell proliferation and migration, and inhibition of collagenolysis leading to inhibition of both angiogenesis and tumor cell growth.

Sharks have inhabited the oceans for many millions of years and are noted to be naturally resilient to disease and trauma (Pettit and Ode, 1977). Because of their impressive survival record and since their skeleton is composed entirely of cartilage (which is believed to contain anti-angiogenic factors) they have become a focus of study of investigators in cancer research (Prieur et al., 1976; Lee and Langer, 1983; Mathews, 1992). Shark cartilage therapy has been widely used for the treatment of a variety of illnesses (such as, rheumatoid arthritis and other auto-immune diseases, psoriasis, scleroderma, AIDS, various forms of cancer), as an anti-inflammatory agent, in wound healing and for prophylactic purposes as a preventive measure against disease. During the Chantilly conference, which was sponsored by the NIH on alternative therapies, investigators reported that about 50,000 Americans were using shark cartilage at an annual cost of about $\$ 7,000$ or more, and that these numbers were expected to increase 
through the following years (Workshop on Alternative Medicine. Washington, DC: US Government Printing Office; 1992). However, the effectiveness of shark cartilage for the treatment of human disease is still very controversial (Blackadar, 1993; Markman, 1996; Ernst, 1998). Comprehensive data, including reliable dose-response data, are still unavailable (Ernst, 1998). There is no convincing evidence that shark cartilage offers any therapeutic or prophylactic benefit. It is possible that it might be harmful when taken during certain disease states, such as chronic inflammatory diseases.

Patients suffering from malignant, chronic and/or degenerative diseases as well as healthy people are taking shark cartilage for therapeutic and prophylactic purposes, and the use of shark cartilage is increasing. This observation disturbs some investigators, who are concerned that the increasing demand for shark cartilage will endanger the survival of shark species. Shark populations are diminishing, especially in the Gulf of Mexico, and much of this depletion is the result of years of unregulated killing of sharks for their fins or by sport fishermen (Mathews, 1992; Campagno, 1999). Sharks are particularly vulnerable because they have a relatively low reproductive capability, are slow to reach sexual maturity, and have long reproductive cycles (Simpfendorfer, 1998). The demand for shark cartilage as a therapeutic agent and prophylactic substance increases the pressure on shark population, which are hunted to secure large amounts of cartilage for commercial use. Sharks maintain an important relationship with the ocean environment, not only by controlling fish overpopulation, but also by ridding the ocean of diseased or injured fish, and their endangerment could result in major ecological problems (Mathews, 1992; Olsen, 1999; Tricas, 1999). Since the short and long-term effects of shark cartilage are not known, the indiscriminating killing of sharks is presently not medically 
justifiable. Nevertheless, a preparation of shark cartilage has been shown to play a scavenger role for reactive oxygen species, thus, protecting cells against hydrogen peroxide-induced damage and mutagenesis, which are processes involved in the pathogenesis of several degenerative diseases (Gomes et al., 1996; Felzenszwalb et al., 1998).

There are very few publications showing the effects of cartilage on the immune system. Rosen et al. (1988) found that Catrix-S enhanced T-cell dependent and T-cell independent antibody responses in mice, in a dose-dependent manner, and that this immunomodulatory effect appeared to be related to chondroitin sulfate present in Catrix. Fontenele et al. (1996) observed an anti-inflammatory and significant analgesic activity of a water-soluble fraction (WSF) from shark cartilage. The experiments consisted of oral administration of WSF from shark cartilage to rats one hour before the animals were challenged with carrageenan and dextran to induce inflammation. The challenge substances were injected in the paws of the test animals and the inhibition of edema was evaluated. Furthermore, during the same study, mice were treated orally with WSF from shark cartilage one hour before they were injected intraperitoneally with acetic acid to evaluate the analgesic response, by observing significant reduction in the number of writhings after treatment in test animals compared to the untreated controls. They also demonstrated that the effects noted are due to a peptide, and are nitric oxide systemdependent (Fontenele et al., 1997).

More recently, Chen et al. (2000) have investigated the effects of shark cartilage extract on endothelial cell attachment and spreading properties. Cell-substratum adhesion is a critical step during cell growth, development, differentiation, and cancer metastasis. 
The adhesion process is mediated by the formation of focal adhesions (FAs), which involves the binding of cell surface receptor integrins to the extracellular matrix via their extracellular domains (Hynes, 1992). It was found that shark cartilage extract both induces cell detachment by reorganization of FAs and stress fibers, and interferes with cell attachment and spreading by decreasing FA formation and preventing stress fiber formation.

The role of shark cartilage as a potential cancer treatment became very controversial when certain investigators questioned the effectiveness of it on tumors, mainly because they doubted whether the proteins responsible for the antiangiogenic activity reach the blood stream, since shark cartilage preparations are taken orally and are composed primarily of macromolecules, which normally are too large to be absorbed by the intestinal tract. Scientists were critical of the lack of reliable dose-response data, bioavailability studies, and the presence of binding agents and fillers in the cartilage preparations, which do not have any antiangiogenic activity (Mathews, 1993; Blackadar, 1993; Markman, 1996; Ernst, 1998; Simone et al., 1998). Several investigators have reported on the absorption of intact macromolecules by the intestinal tract after their oral ingestion (Warshaw et al., 1974; Gardner, 1988). In an initial study (Baici et al., 1992), the bioavailability of oral chondroitin sulfate, the major glycosaminoglycan present in cartilage, was investigated. It was shown that chondroitin sulfate, derived from oral administration is not absorbed as an intact molecule from the mammalian digestive tract. However, dermatan sulfate, another glycosaminoglycan of relatively large molecular weight, was shown to be absorbed after oral administration and a wide range of 
molecular weight (from 7,500 to 20,000 Daltons) of different compounds reached the blood stream (Volpi, 1996).

The inhibition of angiogenesis following oral ingestion of shark cartilage has been studied. A rat model was used to demonstrate for the first time that oral administration of powdered shark cartilage has a potent inhibitory effect on angiogenesis (Davis et al., 1997). Rats were fed with ground rat food, supplemented or not with shark cartilage, two weeks prior to the induction of angiogenesis in the avascular mesenteric window with the compound $48 / 80$ twice daily for 4.5 days. The mesenteric windows were surgically removed and a positive reduction of angiogenesis was shown by light microscopy. In humans, the bioavailability of the antiangiogenic component was demonstrated after the oral administration of a liquid cartilage extract to healthy males (Berbari et al., 1999). This was a prospective study, randomized, controlled, double-blind trial using 29 healthy volunteers. Subjects were randomized into three groups, and each ingested placebo and two different doses of shark cartilage extract on a daily basis for 23 days. On the twelfth day, an inert polyvinyl alcohol ((PVA) sponge implant was inserted subcutaneously into the left arm and removed on the $23^{\text {rd }}$ day. After the implant was removed, it was divided in three parts for analysis as an indirect measurement of angiogenesis. The middle portion was preserved in formalin and used for the measurement of endothelial cell density using monoclonal antibody staining. The other two portions were used for hydroxyproline (marker of collagen deposition) and total protein measurement. Evaluation of the PVA implant sections showed a significant reduction of endothelial cell density in groups that were administered the liquid cartilage extract. The authors concluded that their study is the first to provide evidence of the bioavailability of the cartilage-derived antiangiogenic 
factor after oral administration in humans. It should be noted, however, that the migration of endothelial cells might be the indirect result of factors induced by cartilage rather than the direct effect of a component of shark cartilage.

The use of shark cartilage in other disease states such as psoriasis and rheumatoid arthritis has been also evaluated. Dupont et al. (1998) investigated angiogenesis inhibition by extracts of shark cartilage. They tested an active agent, termed $E$-941, for angiogenesis activity using the embryonic vascularization test (a modified CAM), for collagenase activity using a fluorogenic peptide substrate, and last for anti-inflammatory properties using a cutaneous irritation model in humans. Based on their results they suggested that $A E-941$ has anti-angiogenic and anti-inflammatory properties. However, there are discrepancies in the results from different studies and, to date, no controlled clinical trials have been undertaken to assess its effect (Henderson et al., 1999; Deal et al., 1999).

In a recent study (Morris et al., 2000), the effect of therapeutic potential of boron neutron capture therapy, a cancer therapy, in combination with the oral administration of shark cartilage was evaluated. Rats received intracranial tumor implantation and were irradiated with boron neutron capture therapy with or without simultaneous treatment of an aqueous suspension of shark cartilage. The study concluded that shark cartilage alone significantly increased the survival time of tumor-bearing rats owing to its antiangiogenic effect; however, boron neutron capture therapy was not enhanced by the combination with shark cartilage. In 1998, a phase I/II clinical trial was launched to evaluate the safety and efficacy of shark cartilage treatment of patients in advanced stage of cancer and who had previously been treated, or had recurrent and/or metastatic cancer of the lungs, 
breasts, colorectum, prostate, bladder, brain or non-Hodgkin's lymphoma (Miller et al., 1998). This was an open label, non-randomized study that involved 60 adult patients with advanced (stage III to IV) cancer, who were treated with shark cartilage for 12 weeks. Patients of the study were not on conventional anticancer therapy at the time of the trial, and had previously not used shark cartilage. The results of the study showed no toxic effect of shark cartilage in most patients (measured by hematological, biochemical and immunological parameters) and mild adverse effects primarily from gastrointestinal origin. However, no significant anticancer activity was noted in these patients. Between the end of 1996 and 1998, phase I/II clinical trials were developed in Canada using a liquid extract from shark cartilage called $A E-941 /$ Neovastat (Æterna Laboratories). These studies included 186 refractory lung and prostate cancer patients, 142 refractory solid tumor patients, 49 psoriasis patients and 10 macular degeneration patients. The extract was administered orally by itself, or in combination with either chemotherapy or radiotherapy on a daily basis for a minimum duration of 3 months or lasting for more than 3 years in some cases. The investigators suggested that results fron the study were positive and the clinical results indicated that $A$-941/Neovastat has an excellent safety and tolerability profile (appendix ii). A phase III clinical trial is undergoing in Canada and the United States using the same preparation. This is a randomized study in which cancer patients are administered Neovastat in combination with chemotherapy drugs and radiation treatment to test the effectiveness of the extract in increasing patient survival. The control group receives in place of Neovastat a corresponding amount of placebo. All patients receive standard chemotherapy followed by radiation treatment in combination with the chemotherapy (Neovastat, Aeterna Laboratories, Quebec, Canada). At this 
moment, the oral administration of shark cartilage has more often been evaluated as a complementary therapy, in combination with conventional therapies, which is more reasonable believing that cartilage does not have any direct effect on tumor cells, but rather inhibits angiogenesis that limits tumor growth and metastasis.

An important facet of shark cartilage administration, which has not been addressed comprehensively by investigators, is the effect of shark cartilage on normal immune function, particularly when taken long term. A systematic study to determine its affect on various cell types, their cytokine response, phagocytic and chemotactic ability, proliferative and apoptotic response has not been carried out.

Tumor necrosis factor- alpha (TNF- $\alpha$ ) is a key mediator of inflammation and is produced by the mammalian host in response to injury or invasion by microbes, parasites or neoplasia. TNF- $\alpha$ is a cytokine produced by many cell types after appropriate stimulation. The monocytes/macrophages are the major source when stimulated mainly with lipopolysaccarides (LPS) and phorbol diesters. Mast cells and neutrophils also produce TNF- $\alpha$ in response to LPS stimulation. Other hematopoietic cells of lymphocytic origin, such as T-cells, B-cells and natural killer (NK) cells, also produce TNF- $\alpha$ in response to stimulation with phorbol diesters, phytohemagglutinin and concanavalin A, but not in response to LPS (Sidhu and Bollon, 1993). The biological effects of TNF- $\alpha$ include cytotoxicity through antiproliferative effect and induction of necrotic or apoptotic cell death, differentiation of many cell types, growth stimulation of a number of normal and tumor cells, antiviral activity through lysis of viral infected cells, immunomodulatory and pro-inflammatory activity, gene induction and killing of tumor cells (Beyaert and 
Fiers, 1998). The antitumor activity of TNF- $\alpha$ in vivo depends primarily on the ability of TNF- $\alpha$ to cause vascular changes in the tumor causing a hemorrhagic necrosis of the tumor. The hemorrhagic necrosis might be caused by direct toxic effect and activation of procoagulant activity in tumor endothelium, and by activating antitumor immune response of host cells, activating macrophages, cytotoxic T-cells, natural killer cells and neutrophils. The antitumor effect can be further enhanced by other cytokines, such as interleukin-1 (IL-1) and IL-6, induced by TNF- $\alpha$ (Sidhu and Bollon, 1993; Beyaert and Fiers, 1998). However, in case of overreaction of the host or deficiency of a natural autoregulatory network, TNF- $\alpha$ has several potent deleterious effects and is implicated as a mediator of acute and chronic autoimmune diseases and inflammatory conditions (Beyaert and Fiers, 1998). In the case of rheumatoid arthritis, TNF- $\alpha$ is often present at the site of inflammation and when it is blocked with anti- TNF- $\alpha$ antibody, down regulation of several pro-inflammatory agents occurs leading to local beneficial effects (Feldmann and Maini, 1999). Patients with active psoriasis often have increased TNF- $\alpha$ and IL-6 levels in the psoriatic plaques, and even in the plasma.

TNF- $\alpha$ and shark cartilage have independently, a direct antiproliferative effect in endothelial cells. When shark cartilage and TNF- $\alpha$ are added to a cell culture to stimulate endothelial cells in vitro, a synergic effect is observed in reducing cell proliferation measured by ${ }^{3} \mathrm{H}$-thymidine incorporation by human umbilical vein endothelial cells (HUVEC) (McGuire et al., 1996). The production of TNF- $\alpha$ by endothelial cells stimulated with shark cartilage, or the synergic effect of shark cartilage combined with TNF- $\alpha$, may play a role in regression of growing tumors and remission of other 
degenerative diseases, through a direct effect of both substances on angiogenesis by inhibiting endothelial cell proliferation. An earlier study carried out in our laboratory showed that shark cartilage extracts (acid, salt-soluble and phosphate-buffered saline extracts), prepared from commercial sources of shark cartilage, stimulated human leukocytes in vitro to release significant levels of TNF- $\alpha$, which could be detected in cell culture supernatants by ELISA (Simjee, 1997; Simjee and Smith, 1997). The highest TNF- $\alpha$ response was obtained with the acid extract. It is not known what other cytokines are induced in vitro by shark cartilage and whether the response is associated with the activation of any particular cell type.

TNF- $\alpha$ is a cytokine typically produced in vivo during T helper-1 cellular (Th-1) response, i.e. an inflammatory response. Helper T cells can be classified in two subsets, Th-1 and Th-2, based on their pattern of cytokine synthesis when stimulated by antigens (Gajewski et al., 1989). As cytokines are major determinants of the functions of the $\mathrm{T}$ cells that produce them, these patterns lead to different properties of the $T$ cell subsets. Th-1 cells mediate several functions involved in cytotoxicity and local inflammatory reactions, therefore, being particularly effective at combating viruses and intracellular bacteria and parasites (Mosmann and Coffman, 1989). In general, a strong Th-1 response in the absence of any Th-2 response might be expected to result in delayed-type hypersensitivity (DTH) with little or no antibody production. In contrast, a Th-2 response leads to high general antibody levels, including the production of $\operatorname{IgE}$ and associated eosinophilia, being more effective against extracellular bacteria and in inducing protective humoral immunity. Antibody production and DTH reactions are often mutually exclusive during immune responses in mice, and this can be partially explained 
by cross-inhibition of Th-1 and Th-2 cells (Street and Mosmann, 1991). Although strongly biased Th-1 or Th-2 responses would be expected to result in clearly distinguishable immune responses, many normal responses in humans may involve a mixture of the two types of cells. The isotype patterns may depend on the ratio of Th-1 and Th-2 activation (Mosmann and Coffman, 1989; Swain et al., 1991). In case of cytokine induction by shark cartilage, it is important to identify the factors being induced, since the pattern of induction reflects the type of cells responding, which in turn will determine the potential use or harm to the host.

IL-4 plays an important biological role as it modulates cytokine production by $\mathrm{T}$ cells, B cells and NK cells, monocytes/macrophages, endothelial cells and fibroblasts (Banchereau and Rybak, 1994). Unlike TNF- $\alpha$, IL-4 is a cytokine that is typically secreted in vivo during a Th-2 cellular response, i.e. an anti-inflammatory response. IL-4 which is involved in the differentiation of Th-2 cells, originates from basophils/mast cells while interferon gama (IFN- $\gamma$ ) and IL-2, which induce the maturation of Th-1 cells originate from NK cells and macrophages, respectively. An important feature of Th-1 and Th- 2 cells is the ability of one subset to regulate the activities of the other. It occurs at the level of the effector cells that are triggered by these subsets, as indicated by the inhibitory effects of IFN- $\gamma$ on IL-4-induced B cell activation or those of IL-4 on IL-2 induced T and B lymphocyte proliferation (Banchereau and Rybak, 1994). In a study carried out by Abehsira-Amar et al. (1992), they demonstrated that IL-4 positively controls the differentiation of Th- 0 into Th- 2 cells and negatively controls the differentiation of Th- 0 into Th- 1 cells. They neutralized secreted IL-4 with anti-IL-4 monoclonal antibody and completely prevented the differentiation of Th- 0 into Th- 2 cells, but permitted the 
development of Th-1 cells. Based on their results, they suggested that IL-4 is the principal factor that controls the differential development of Th- 0 cells into Th- 1 and Th2 cells. In vivo studies have also demonstrated an important anti-tumor effect for IL-4, and its recombinant form is well tolerated by advanced cancer patients (Redmond et al., 1992; Banchereau and Rybak, 1994). In addition to its potential use in the treatment of cancer, IL-4 may be an effective agent in the treatment of a variety of diseases due to its immunomodulatory and anti-inflammatory properties. In particular, the inhibitory effects of IL-4 on the in vivo and in vitro production of cytokines, such as IFN- $\gamma$ and IL-2, provide a strong rationale for its use in chronic inflammatory diseases such as rheumatoid arthritis or other inflammatory diseases where an excess of Th-1 activity is observed. IL4 thus can equilibrate the balance between Th- 1 and Th- 2 cellular response (AbehsiraAmar et al., 1992, Banchereau and Rybak, 1994).

The present study in addition to examine cytokine response, will also examine another important biological phenomenon, that is, apoptosis. The induction of apoptosis of human leukocytes by shark cartilage extract will be investigated. The biochemical hallmark of apoptosis is the internucleosomal fragmentation of genomic DNA, producing fragments that are multiples of approximately $185 \mathrm{bp}$. These fragments can readily be demonstrated by agarose gel electrophoresis of DNA isolated from apoptotic cells, which appear as a typical ladder pattern (Arends et al., 1990). Apoptosis is also characterized morphologically by a series of typical events, such as shrinkage of the cell and the nucleus as well as condensation of nuclear chromatin into sharply delineated masses that become marginated against the nuclear membrane. The nucleus condenses progressively, the cell detaches from the surrounding tissue and its outline becomes convoluted to form 
extensions that separate and seal the plasma membrane forming the apoptotic bodies (Saraste \& Pulkki, 2000). All these morphological changes can be readily detected by light microscopy. Apoptosis occurs under physiological conditions in normal cells to maintain homeostatic regulation of normal tissue. Apoptotic deletion of lymphocytes serves important normal function in the immune system. Immature thymocytes have been shown to undergo apoptosis when stimulated via T-cell receptor at a critical stage in their maturation, and it is the mechanism responsible for elimination of autoreactive T-cell clones during development of cellular immune self-tolerance (Tomei and Cope, 1991; Saraste \& Pulkki, 2000). The loss of normal apoptosis is an important aspect of tumor progression. Tumor cells have to acquire the ability to resist apoptosis in order to progress. The lost of normal balance between mitosis and apoptosis leads to tumor development. Apoptosis is crucial to maintain normal cell function. Cells that have important DNA mutations, which cannot be repaired, undergo apoptosis. Senescent cells and aging neutrophils are eliminated by apoptosis (Lundberg \& Weinberg, 1999). Because this biological function is a crucial aspect of the normal cell cycle, this study plans to evaluate the effect of shark cartilage on apoptosis of human leukocytes.

Shark cartilage therapy is widely used for the treatment of a variety of disease states and for prophylaxis. In the latter case, healthy people are taking it indiscriminately without knowing the short and long-term effects of this substance. Shark cartilage preparations are easily available from drugstores and health food stores where they are sold as a food supplement and do not require FDA approval. The effectiveness of shark cartilage as a treatment for a variety of human disease is still very controversial, mostly because complete and reliable dose-response data is unavailable. At present, there is no 
evidence that shark cartilage offers any benefit for the treatment of human disease or as a prophylactic agent. In fact, preliminary studies indicate that it is possible that shark cartilage might cause harm if taken during certain disease states, such as inflammatory chronic diseases, where undesirable immune response may be up regulated. TNF- $\alpha$ and IL-4 are cytokines that are characteristic of two different types of immune responses, Th1 and Th- 2 respectively. The first is associated with inflammation, while the latter is typically produced in anti-inflammatory responses along with the production of antibodies. The two are believed to be mutually exclusive (Mosmann and Coffman, 1989). Previous in vitro studies have shown that shark cartilage induces human leukocytes to produce TNF- $\alpha$, a cytokine that, in vivo, characterize a Th-1 response (Simjee and Smith, 1997).

Based on these observations, it is necessary to investigate further the effect of shark cartilage on components of the human immune system initially through in vitro studies, followed by in vivo evaluation to determine the long term consequences of its administration on human disease and on the health of normal individuals. The main focus of the proposed study is to examine the types of in vitro cellular responses induced by shark cartilage. The study will determine whether shark cartilage will induce cells to produce IL-4, a Th-2 type cytokine. Furthermore, in addition to TNF- $\alpha$, a cytokine characteristic of Th-1 type response, the study will also examine the effect of shark cartilage on in vitro production of IFN- $\gamma$ by stimulated cells. Since tumor development results from uncontrolled proliferation of affected cells by their loss of the normal cell apoptotic machinery, this study will also examine the influence of shark cartilage on apoptosis of normal competent immune cells. Similarly, cell proliferation, too, will be 
assessed following treatment with and/or in the presence of shark cartilage. The study will also attempt to distinguish the degree of responsiveness to shark cartilage by different cell types by using specific cell-enriched fractions of leukocytes to set up cell cultures. 


\section{Material and Methods}

\section{Blood Donors}

Consent forms from all human subjects who donated blood to be used during this study are present in appendix iii.

\section{Chemical and Reagents}

All chemicals and reagents used in this study are listed in appendix iv.

\section{Sterilization}

All solutions, tubes and glass containers used throughout the study were sterilized by autoclaving at $121^{\circ} \mathrm{C}, 15 \mathrm{psi}$ for 15 minutes or filter sterilized through $0.45 \mu \mathrm{m}$ Nalgene filters.

\section{Cell Culture Medium}

Human peripheral blood leukocytes were cultured in RPMI-1640 medium (Life Technologies, Inc., Rockville, MD), supplemented with $300 \mathrm{mg} / \mathrm{ml}$ glutamine, $25 \mathrm{mM}$ HEPES, $10 \%$ heat-inactivated newborn calf serum (Life Technologies, Inc., Rockville, MD), $100 \mathrm{U} / \mathrm{ml}$ penicillin and $100 \mu \mathrm{g} / \mathrm{ml}$ streptomycin (Life Technologies, Inc., Rockville, MD). Medium was filter sterilized.

\section{Shark Cartilage Extract}

Acid extract of shark cartilage (ASC) was prepared from commercially available shark cartilage capsules marketed as Cartilade (Solgar Laboratory, Leonia, NJ). Three grams of shark cartilage were dissolved in $50 \mathrm{ml}$ of $0.5 \mathrm{M}$ acetic acid containing $0.03 \%$ toluene, $\mathrm{pH} 4.2$ and incubated overnight at $4^{\circ} \mathrm{C}$ with continuous stirring. The preparation 
was centrifuged at $900 \mathrm{xg}$ for 10 minutes at $4^{\circ} \mathrm{C}$, the insoluble precipitated material was discarded and the supernatant filtered through a $0.45 \mu \mathrm{m}$ filter, followed by filtration through a $0.22 \mu \mathrm{m}$ filter (Corning Costar Corp., Cambridge, MA) using a needle and syringe. Initially, the filtered extract was dialyzed overnight at $4^{\circ} \mathrm{C}$, using a Slide-ALyser Cassette (Pierce Chemical Co., Rockford, IL) with a molecular cut off of 3,500 $\mathrm{kDa}$, against Tris $0.02 \mathrm{M}, \mathrm{pH} 7.4$. The dialyzed samples were filtered a final time through a $0.22 \mu \mathrm{m}$ filter and stored at $-20^{\circ} \mathrm{C}$. Total protein concentration was determined for the dialyzed, filter-sterilized extract. Before use in cell culture extract preparations were dialyzed for 4 hours at $4^{\circ} \mathrm{C}$ against RPMI-1640 supplemented with glutamine and HEPES. Furthermore, each extract preparation was tested for endotoxin using the EToxate kit before it was used as a stimulant in the cell cultures.

\section{Protein Determination}

Determination of total protein concentration of the acid shark cartilage extract was performed using the BCA-Protein assay (Pierce Chemical Co., Rockford, IL) according to the manufacture's recommended protocol. Briefly, $0.1 \mathrm{ml}$ of the acid shark extract sample and of each concentration of the BSA standards provided in the kit were individually mixed with $2.0 \mathrm{ml}$ of working the reagent, prepared by mixing 50 parts of reagent $A$ (sodium carbonate, bicarbonate, and sodium tartarate in $0.1 \mathrm{~N} \mathrm{NaOH}$ ) with one part of reagent $\mathrm{B}$ ( $4 \%$ copper sulfate solution). The mixture was incubated at $37^{\circ} \mathrm{C}$ for 30 minutes. After incubation, samples were allowed to cool to room temperature and the absorbance of each test sample and control standards was measured at $562 \mathrm{~nm}$ using an Ultrospec 3000 spectrophotometer (Pharmacia Biotech Inc., Alameda, CA). Plotting the optical density readings of each standard against its corresponding concentration 
generated a standard curve, which was used to determine the protein concentration in $\mu \mathrm{g} / \mathrm{ml}$ of the cartilage extract from its optical density. The concentrations of BSA standards used to prepare the standard curve were $100 \mu \mathrm{g} / \mathrm{ml}, 200 \mu \mathrm{g} / \mathrm{ml}, 400 \mu \mathrm{g} / \mathrm{ml}, 600$ $\mu \mathrm{g} / \mathrm{ml}, 800 \mu \mathrm{g} / \mathrm{ml}$ and $1000 \mu \mathrm{g} / \mathrm{ml}$.

\section{Assay for Endotoxin}

To detect and quantify the level of endotoxin in test reagents and samples, the EToxate test kit (Limulus Amebocyte Lysate Assay, Sigma Chemical Company, St. Louis, $\mathrm{MO}$ ) was used. The sensitivity of the test ranges from 0.05 to 0.1 endotoxin units (EU) per ml. Briefly, $0.1 \mathrm{ml}$ of each test sample was mixed with $0.1 \mathrm{ml}$ of E-Toxate working solution (dry concentrate from Limulus polyhemus reconstituted with endotoxin-free water according to the manufacturer's instruction), and incubated undisturbed at $37^{\circ} \mathrm{C}$ for one hour. After incubation, the tubes were gently inverted 180 degrees to observe evidence of gelation. The formation of a hard gel, which permits complete inversion of the tube without disruption of the gel, constitutes a positive test. All other forms or degrees of gelation ranging from a soft gel to a clear fluid are considered negative. Endotoxin standards (LPS of E. coli 055:B5) were used as positive controls in concentrations of $0.5 \mathrm{EU} / \mathrm{ml}, 0.25 \mathrm{EU} / \mathrm{ml}, 0.125 \mathrm{EU} / \mathrm{ml}, 0.06 \mathrm{EU} / \mathrm{ml}, 0.03 \mathrm{EU} / \mathrm{ml}$ and $0.015 \mathrm{EU} / \mathrm{ml}$. Endotoxin-free water was used as a negative control. Test samples were also tested for the presence of E-Toxate inhibitor(s) by mixing $0.01 \mathrm{ml}$ of $4 \mathrm{EU} / \mathrm{ml}$ standard with $0.1 \mathrm{ml}$ of sample and $0.1 \mathrm{ml}$ of E-Toxate working solution. The formation of a hard gel indicates the absence of an inhibitor in the test sample. 


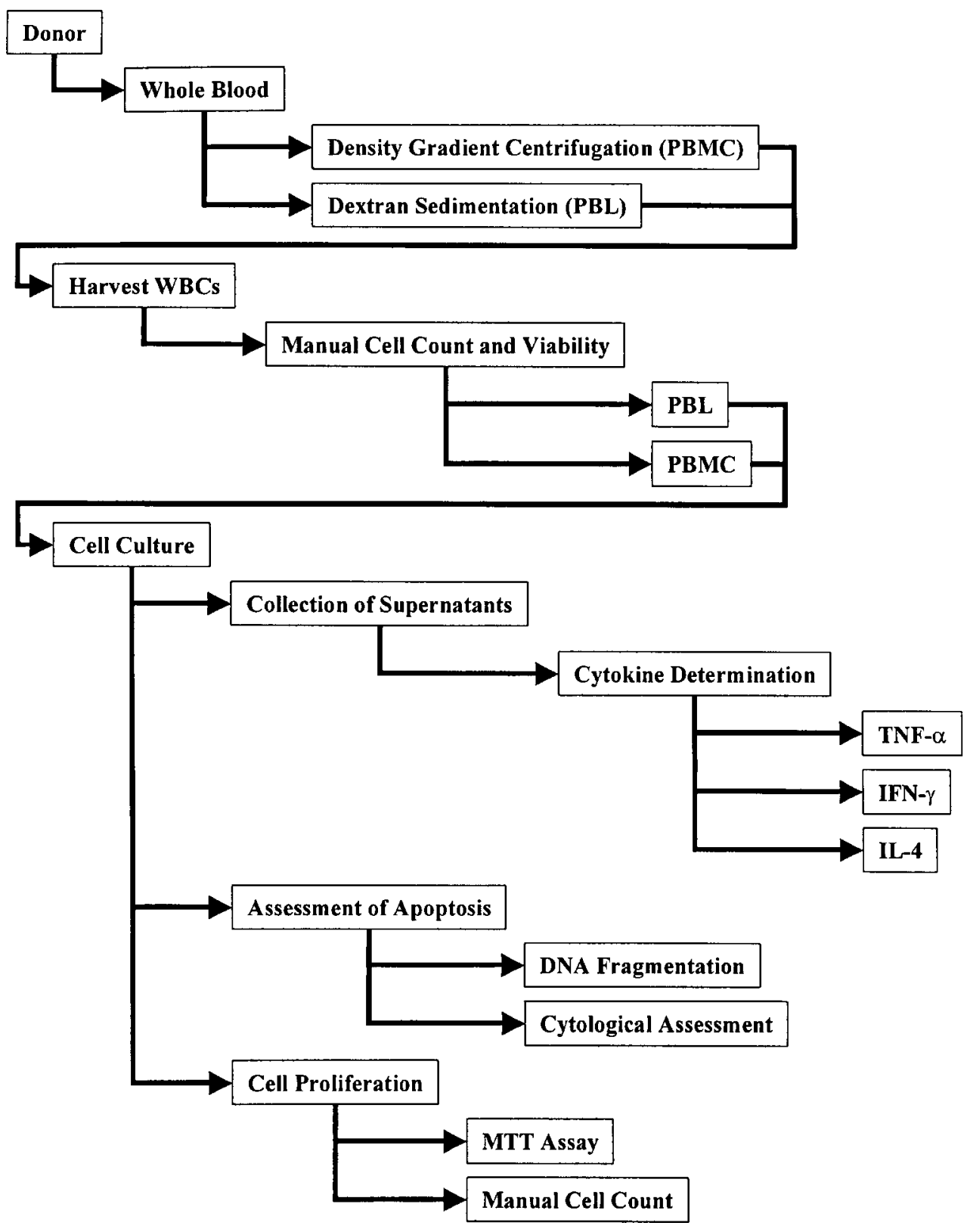

Figure 1: Summary of protocols used during experimental work 


\section{Isolation of Human Peripheral Blood Leukocytes}

Protocols employed for the isolation of leukocytes follows below. A flow chart summarizing the experimental approach taken in this study is outlined in figure 1.

\section{Protocol A}

This protocol was followed to isolate a heterogeneous population of leukocytes (PBL) from whole blood. Freshly drawn heparinized human blood (containing $20 \mathrm{U}$ heparin/ml whole blood) was mixed with an equal volume of 3\% Dextran (MW 500,000, Sigma Chemical Company, St. Louis, $\mathrm{MO})$ in sterile physiological saline $(0.15 \mathrm{M} \mathrm{NaCl})$. Red blood cells (RBC) were allowed to settle by gravity at room temperature for 30 minutes. The cloudy supernatant containing leukocytes was harvested and transferred to a $15 \mathrm{ml}$ polypropylene plastic tube (Corning Costar Corporation, Cambridge, MA), and then centrifuged at $400 \mathrm{xg}$ for 10 minutes at $4^{\circ} \mathrm{C}$. The supernatant was discarded and the cell pellet gently resuspended in $7 \mathrm{ml}$ of $0.2 \% \mathrm{NaCl}$ for 30 seconds to lyse residual contaminating RBCs. Immediately following $\mathrm{RBC}$ lysis, $7 \mathrm{ml}$ of $1.6 \% \mathrm{NaCl}$ (equal volume to $0.2 \%$ solution used) was added to the cell suspension to bring the suspension to physiological isotonicity $(0.85 \% \mathrm{NaCl}$ concentration) for human leukocytes. The cell suspension was centrifuged at $400 \mathrm{x}$ f for 10 minutes at $4^{\circ} \mathrm{C}$. The $\mathrm{RBC}$ lysing procedure was repeated once more, the supernatant discarded and the cell pellet washed once using RPMI-1640 medium. Cells were resuspended in $12 \mathrm{ml}$ of RPMI-1640 medium and a manual cell count was performed using a hemacytometer. The volume of the cell suspension was adjusted to give a final concentration of $1.2-1.3 \times 10^{6}$ cells $/ \mathrm{ml}$. Isolated leukocytes were used immediately to set up cell cultures. 


\section{Protocol B}

This protocol was employed to isolate a mononuclear cell-enriched fraction (PBMC) of leukocytes. Freshly drawn heparinized human blood (containing $20 \mathrm{U}$ heparin/ml of heparin) was layered onto the surface of an equal volume of Histopaque1077 (Sigma Chemical Company, St. Louis, MO) and centrifuged at $400 \mathrm{x} \mathrm{g}$ for 30 minutes at $20^{\circ} \mathrm{C}$, with the centrifuge break off. The PBMC-rich interface band, located between the gradient mix and the plasma, was aspirated with a Pasteur pipette and transferred into a clean $15 \mathrm{ml}$ polypropylene plastic tube. Sterile physiological saline was added to the cell suspension and the suspension centrifuged at $400 \mathrm{x}$ g for 10 minutes at $4^{\circ} \mathrm{C}$. The supernatant was discarded and the cell pellet was washed once more with RPMI-1640 medium. Cells were resuspended in $6 \mathrm{ml}$ of RPMI-1640 medium and a manual cell count was performed using a hemacytometer. The volume of the cell suspension was adjusted to contain $1.2-1.3 \times 10^{6}$ cells $/ \mathrm{ml}$ and used immediately to set up cell cultures.

\section{Protocol C}

This protocol was an alternative method to protocol $\mathrm{B}$ for the isolation of a mononuclear cell-enriched fraction of leukocytes from whole blood. Freshly drawn heparinized human blood was mixed with an equal volume of $3 \%$ Dextran in sterile physiological saline $(0.15 \mathrm{M} \mathrm{NaCl})$. $\mathrm{RBCs}$ were allowed to settle by gravity at room temperature for 30 minutes. The cloudy supernatant containing leukocytes was harvested and transferred to a $15 \mathrm{ml}$ polypropylene plastic tube, and then mixed with an equal volume of physiological saline $(0.15 \mathrm{M} \mathrm{NaCl})$. The mixture was centrifuged at $400 \mathrm{xg}$ for 10 minutes at $4^{\circ} \mathrm{C}$ to remove the Dextran. The supernatant was discarded and the cell 
pellet gently resuspended in $5 \mathrm{ml}$ of physiological saline. The leukocyte-saline mixture was layered onto the surface of an equal volume of Histopaque-1077 and centrifuged at $400 \mathrm{x}$ g for 30 minutes at $20^{\circ} \mathrm{C}$, with the centrifuge break off. The PBMC rich interface band located between the gradient mix and the saline was aspirated with a Pasteur pipette and transferred into a clean $15 \mathrm{ml}$ polypropylene plastic tube. The cell suspension was washed by the addition of $7 \mathrm{ml}$ of sterile physiological saline and centrifuged $(400 \times \mathrm{g}, 10$ minutes at $4^{\circ} \mathrm{C}$ ). The supernatant was discarded and cells were washed once more with RPMI-1640 medium. The cell pellet was resuspended in $2 \mathrm{ml}$ of RPMI-1640 medium and a manual cell count was performed using a hemacytometer, and cell viability was assessed using the trypan blue exclusion test.

\section{Cell Viability}

The cell viability of all standardized cell suspensions was determined by the Trypan Blue exclusion test, which consists of mixing $0.1 \mathrm{ml}$ of cell suspension with 0.1 $\mathrm{ml}$ of $0.4 \%$ Trypan Blue (Sigma Chemical Company, St. Louis, MO) in physiological saline. Viability is confirmed by exclusion of the dye by cells. The percentage of viable cells was calculated by loading a hemacytometer chamber with the dye-treated cell suspension and counting 200 cells to determine the percentage of cells that excluded the dye. The percentage of viable cells was calculated using the formula:

$$
\% \text { viable cells }=\frac{\text { number of cells excluding the dye }}{\text { total number of cells counted }} \times 100
$$

Only cell suspensions with a viability of $95 \%$ or higher were used to set up cell cultures. 


\section{Leukocyte Cultures}

In vitro leukocyte cultures were set up to study cell proliferation, apoptosis and induction of cytokines. As culture conditions varied slightly depending on the purpose, details are provided below.

\section{Cell Proliferation}

Leukocyte proliferation was measured directly by manual cell counts and indirectly employing the MTT assay, which is based on the ability of living cells to reduce the yellow soluble salt MTT (3-(4,5-dimethylthiazol-2-yl)-2,5-diphenyl tetrazolium bromide) to a purple-blue insoluble formazan precipitate, by dehydrogenase activity present only in metabolically viable cells. PBMC fraction of leukocytes were cultured in 24-well flat bottom tissue culture plates. Cell cultures were set up in duplicate. Each well contained $200 \mu \mathrm{l}$ of cell suspension ( $4 \times 10^{5}$ cells/well), $100 \mu \mathrm{l}$ of growth medium (RPMI-1640 supplemented with $300 \mathrm{mg} / \mathrm{ml}$ glutamine, $25 \mathrm{mM}$ HEPES, $10 \%$ newborn calf serum, $100 \mathrm{U} / \mathrm{ml}$ penicillin and $100 \mu \mathrm{g} / \mathrm{ml}$ streptomycin) and $50 \mu \mathrm{l}$ of the test or control stimulant. The mitogens LPS (E. coli 026:B6, Sigma Chemical Company, St. Louis, MO) and Concanavalin A (ConA, Sigma Chemical Company, St. Louis, MO) were used at a concentration of $5 \mu \mathrm{g} / \mathrm{ml}$ as positive controls and prepared in culture medium (as above) without calf serum. The culture medium control was prepared by replacing the sample with medium. Cell cultures were set up in duplicate as follows:

1. Test culture: $200 \mu \mathrm{l}$ cell suspension $+100 \mu \mathrm{l}$ medium $+50 \mu \mathrm{l}$ ASC

2. Positive control culture: $200 \mu$ cell suspension $+100 \mu \mathrm{l}$ medium $+50 \mu \mathrm{l}$ LPS or Con A

3. Culture medium control: $200 \mu \mathrm{l}$ cell suspension $+150 \mu \mathrm{l}$ medium 
The culture plates were incubated at $37^{\circ} \mathrm{C}$ for 4,24 and 48 hours in a humidified chamber with $5 \% \mathrm{CO}_{2}$. Following incubation, proliferation was assessed by manual cell counts and the reduction of MTT. For manual cell counts, cells were harvested by gently detaching cells attached to the bottom surface of the well by vigorous pipetting and aspirating the content of each well with a pipette at $0,4,20,24,30$ and 48 hours. A hemacytometer chamber was loaded with the harvested cell suspension for cell count.

\section{MTT Assay}

In vitro cell proliferation was measured by the level of dehydrogenase activity in metabolically viable cells following oxidative burst, which was determined by the MTT assay. Following the incubation of cell cultures (as described above), $35 \mu \mathrm{l}$ of a stock solution of MTT ( $5 \mathrm{mg} / \mathrm{ml}$ in PBS $0.15 \mathrm{M}, \mathrm{pH}$ 7.2) was added to each well and cultures were further incubated $\left(37^{\circ} \mathrm{C}, 5 \% \mathrm{CO}_{2}\right)$ for 4 hours. To dissolve the insoluble formazan crystals that form, $100 \mu 1$ of $10 \%$ SDS in $0.02 \mathrm{M} \mathrm{HCl}$ was added to all wells and the mixtures incubated overnight at room temperature. Once the formazan crystals were completely dissolved, the content of each well was transferred to a microcentrifuge tube and centrifuged at $6,000 \mathrm{x}$ g for 1 minute to remove all cell debris. The clear supernatants $(200 \mu \mathrm{l})$ were transferred to a 96-well microtiter plate and the absorbance read at $570 \mathrm{~nm}$ in an ELISA reader (MRX II, Dynex Technologies Inc., Chantilly, VA), using a reference filter of $630 \mathrm{~nm}$. Absorbance is directly proportional to the level of dehydrogenase activity associated with the oxidative burst, which in turn reflects the number of viable cells present. 


\section{Leukocyte Culture for Cytokine Induction}

Human PBL or PBMC fraction of leukocytes were cultured in 24-well flat bottom tissue culture plates (Falcon, Becton Dickinson \& Corp., Lincoln Park, NJ). Cell cultures were set up in duplicate. Each well contained $200 \mu \mathrm{l}$ of cell suspension $\left(2.4 \times 10^{5}\right.$ cells/well for PBL, and $2.2 \times 10^{5}$ cells/well or $1.36 \times 10^{6}$ cells/well for PBMC prepared by Protocol B), $100 \mu \mathrm{l}$ of growth medium (RPMI-1640 supplemented with $300 \mathrm{mg} / \mathrm{ml}$ glutamine, $25 \mathrm{mM}$ HEPES, $10 \%$ newborn calf serum, $100 \mathrm{U} / \mathrm{ml}$ penicillin and $100 \mu \mathrm{g} / \mathrm{ml}$ streptomycin) and $50 \mu \mathrm{l}$ of test or control stimulant. Positive mitogen response controls for $B$ and $T$ cell stimulation consisted of replacing the test stimulant with specific mitogen. Five $\mu \mathrm{g} / \mathrm{ml}$ of LPS (E. coli 026:B6, Sigma Chemical Company, St. Louis, MO) was added to cultures to stimulate TNF- $\alpha$ and/or IFN- $\gamma$ production. In cultures set up for IL-4 production, $5 \mu \mathrm{g} / \mathrm{ml}$ of Concanavalin A (ConA, Sigma Chemical Company, St. Louis, MO) or $100 \mathrm{nM}$ of phorbol 12-myristate 13-acetate (PMA, Life Technologies, Inc., Rockville, MD) were used. The mitogen stock solutions were prepared in culture medium described above without calf serum. Duplicate cell cultures were set up as follows:

1. Test sample culture: $200 \mu \mathrm{l}$ cell suspension $+100 \mu \mathrm{l}$ medium $+50 \mu \mathrm{l}$ ASC

2. Positive control culture: $200 \mu$ cell suspension $+100 \mu \mathrm{l}$ medium $+50 \mu \mathrm{l}$ LPS or Con A or PMA

3. Mitogen control culture: $300 \mu 1$ medium $+50 \mu \mathrm{l}$ LPS or Con A or PMA

4. Culture medium control: $200 \mu$ l cell suspension $+150 \mu$ medium 
The culture plates were incubated at $37^{\circ} \mathrm{C}$ for $4,8,20,24,30$ and 48 hours in a humidified chamber with $5 \% \mathrm{CO}_{2}$. At each specified time point, cells were harvested by aspirating the contents of each well into a sterile microcentrifuge tube and centrifuging at 6,000 x g for 1 minute (Micromax RF, International Equipment Company, Needham Heights, MA). Supernatants were collected and transferred to sterile microcentrifuge tubes and stored at $-80^{\circ} \mathrm{C}$ until assayed for TNF- $\alpha$, IFN- $\gamma$ and/or IL-4.

\section{Leukocyte Culture for Assessment of Apoptosis}

Human PBMC fraction of leukocytes prepared by Protocol B were cultured in 24well flat bottom tissue culture plates. Cell cultures were set up in duplicate. Each well contained $200 \mu \mathrm{l}$ of cell suspension $\left(1.5 \times 10^{6}\right.$ cells/well $), 100 \mu \mathrm{l}$ of growth medium (RPMI-1640 supplemented with $300 \mathrm{mg} / \mathrm{ml}$ glutamine, $25 \mathrm{mM}$ HEPES, $10 \%$ newborn calf serum, $100 \mathrm{U} / \mathrm{ml}$ penicillin and $100 \mu \mathrm{g} / \mathrm{ml}$ streptomycin) and $50 \mu \mathrm{l}$ of test stimulant. Positive control cultures for apoptosis consisted of replacing the test stimulant with 5 $\mu \mathrm{M} / \mathrm{ml}$ of staurosporine (Sigma Chemical Company, St. Louis, MO) or $5 \mu \mathrm{g} / \mathrm{ml}$ of camptothecin (Sigma Chemical Company, St. Louis, MO), prepared as stock solution initially in DMSO (Sigma Chemical Company, St. Louis, MO). A working solution of apoptosis inducers was prepared in culture medium without calf serum. Duplicate cell cultures were set up as follows:

1. Test sample culture: $200 \mu \mathrm{l}$ cell suspension $+100 \mu \mathrm{l}$ medium $+50 \mu \mathrm{l} \mathrm{ASC}$

2. Apoptosis positive control culture: $200 \mu \mathrm{l}$ cell suspension $+100 \mu \mathrm{l}$ medium + $50 \mu 1$ Staurosporine or Camptothecin

3. Culture medium control: $200 \mu \mathrm{l}$ cell suspension $+150 \mu \mathrm{l}$ medium 
The culture plates were incubated at $37^{\circ} \mathrm{C}$ for 4 hours, 8 hours, 24 hours and 48 hours in a humidified chamber with $5 \% \mathrm{CO}_{2}$. At each specified time point, cells were harvested by resuspending and aspirating the contents of each well into a sterile microcentrifuge tube. The DNA from these cells was isolated using the Apoptotic DNA Ladder kit according to the manufacturer's instructions. The protocol is described later in the isolation of leukocyte DNA.

\section{Preparation of Leukocyte Cytospin monolayers}

Cytospin films of PBL and PBMC (prepared according to Protocols A and B respectively) were prepared for cytological examination of cell types in cultures, and for cytochemical examination of cell types morphological changes characteristic of apoptosis. Single cell layer films on glass slides were prepared by loading each cytospin chamber (Cytopro, Wescor Inc., Logan, UT) with $0.2 \mathrm{ml}$ of cell suspension aspirated from cell cultures growing in 24 well cell culture plate. The chambers were placed in a cytocentrifuge (Cytopro Centrifuge, Wescor Inc., Logan, UT) and cells centrifuged at 32 $\mathrm{x} g$ for 2 minutes onto microscopic slides coated with aminoalkylsilane (Silane-Prep Slides, Sigma Chemical Company, St. Louis, MO). Slides coated with the leukocyte film were air dried at room temperature for approximately 5 minutes, and stained with the Hema 3 staining system (Fisher Scientific Co., Pittsburg, PA), an equivalent to WrightGiemsa staining. Slides were examined by light microscopy. For assessment of morphological changes characteristic of apoptosis, 100 cells were counted on each slide and the number of cells showing visible signs of apoptotic changes (listed below and illustrated in Figure 2), as well as cells showing normal morphology were recorded. 
Morphological assessment of apoptotic change was based on observing one or more of the following morphological criteria for apoptotic cells:

Cell membrane convolutions (blebbing)

Cytoplasmic constriction with a reduction in cell volume;

Nuclei shrinkage, chromatin condensation and nuclear fragmentation;

Formation of apoptotic bodies

\section{Assay for Extracellular Cytokine in Stimulated Cell Cultures}

Cell cultures for cytokine production were set up using either PBL or PBMC fraction of leukocytes. Cells were cultured in 24-well flat bottom tissue culture plates and were set up in duplicate. Each well contained $200 \mu \mathrm{l}$ of cell suspension $\left(2.2 \times 10^{5}\right.$ cells/well prepared by Protocol B), $100 \mu$ of growth medium and $50 \mu \mathrm{l}$ of test or control stimulant. Positive control cultures for TNF- $\alpha$ production consisted of adding five $\mu \mathrm{g} / \mathrm{ml}$ of LPS to cultures. The culture plates were incubated at $37^{\circ} \mathrm{C}$ for $4,8,20,24,30$ and 48 hours in a humidified chamber with $5 \% \mathrm{CO}_{2}$. At each specified time point, cells were harvested by aspirating the contents of each well into a sterile microcentrifuge tube and removing cell debris by centrifuging at $6,000 \mathrm{x} g$ for 1 minute. Culture supernatants were collected and transferred to sterile microcentrifuge tubes and stored at $-80^{\circ} \mathrm{C}$ until assayed for the presence of cytokines.

\section{TNF- $\alpha$ Assay}

A solid-phase enzyme-linked immunosorbent assay (ELISA) using monoclonal antibodies against human TNF- $\alpha$ (Endogen Inc., Woburn, MA) was performed to detect and quantitate the levels of TNF- $\alpha$ in cell culture supernatants. All reagents were provided in the kit. Briefly, $50 \mu$ l of test sample (culture supernatant) or TNF- $\alpha$ standard 
followed by $50 \mu l$ of biotinylated anti-TNF- $\alpha$ antibody reagent were added to each well of a 96-well plate, and incubated for two hours at room temperature $\left(20-25^{\circ} \mathrm{C}\right)$. The plate was washed three times with wash buffer after which $100 \mu$ of streptavidin-horse radish peroxidase (HRP) concentrate was added to all wells. Plate was incubated at room temperature $\left(20-25^{\circ} \mathrm{C}\right)$ for 30 minutes. After incubation, the plate was washed three times again with wash buffer and incubated with $100 \mu$ of tetramethylbenzidine (TMB) substrate solution at room temperature $\left(20-25^{\circ} \mathrm{C}\right)$, in the dark, for 30 minutes. The reaction was stopped by the addition of $100 \mu$ of stop solution to the wells and the O.D. of the reaction mixture of each well was read at $450 \mathrm{~nm}$ using an ELISA reader MRX II (Dynex Technologies Inc., Chantilly, VA). A standard curve was constructed by plotting the average absorbance reading obtained for each TNF- $\alpha$ standard reaction (concentrations of $0,25.6,64,160,400$ and $1000 \mathrm{pg} / \mathrm{ml}$ ) on the vertical axis against the corresponding standard concentration on the horizontal axis. The standard curve was used to determine the concentration of free TNF- $\alpha$ present in the test samples (culture supernatants), from the absorbance readings at $450 \mathrm{~nm}$ obtained for each test sample. All standards and test samples were run in duplicate. The detection sensitivity of the test is $<5$ pg TNF- $\alpha / \mathrm{ml}$.

\section{IFN- $\gamma$ Assay}

A solid-phase ELISA using monoclonal antibodies against human IFN- $\gamma$ (Endogen Inc., Woburn, MA) was performed to detect IFN- $\gamma$ in cell culture supernatants. The assay was set up and carried out in a manner similar to the TNF- $\alpha$ assay, described above. A PBMC suspension was prepared according to Protocol B and cell cultures 
contained $1.36 \times 10^{6}$ cells/well. The concentrations of the standards used to generate the standard curve were $0,25.6,64,160,400$ and $1000 \mathrm{pg} / \mathrm{ml}$. A standard curve was constructed from the average absorbance reading obtained for each IFN- $\gamma$ standard reaction (plotted on the vertical axis) against its corresponding concentration (horizontal axis). The concentration of IFN- $\gamma$ present in the test samples (culture supernatants) was determined from the absorbance readings at $450 \mathrm{~nm}$ obtained for each test sample. All IFN- $\gamma$ standards and test supernatant samples were run in duplicate. The sensitivity of the test was $<5 \mathrm{pg}$ IFN- $\gamma / \mathrm{ml}$.

\section{IL-4 Assay}

Human PBMC fraction of leukocytes were cultured in 24-well flat bottom tissue culture plates. Cell cultures were set up in duplicate. Each well contained $200 \mu 1$ of cell suspension $\left(2.2 \times 10^{5}\right.$ cells/well or $1.36 \times 10^{6}$ cells/well prepared by Protocol B), $100 \mu 1$ of growth medium and $50 \mu \mathrm{l}$ of test or control stimulant. Five $\mu \mathrm{g} / \mathrm{ml}$ of ConA was added to cultures as positive control to induce IL-4 production The culture plates were incubated at $37^{\circ} \mathrm{C}$ for $4,8,20,24,30$ and 48 hours in a humidified chamber with $5 \%$ $\mathrm{CO}_{2}$. At each specified time point, cells were harvested by aspirating the contents of each well into a sterile microcentrifuge tube and centrifuging at $6,000 \mathrm{x} g$ for 1 minute. Culture supernatants were collected and stored in sterile microcentrifuge tubes at $-80^{\circ} \mathrm{C}$ until assayed for IL-4.

A solid-phase ELISA using monoclonal antibodies against human IL-4 (Endogen Inc., Woburn, MA) was performed to detect IL-4 in cell culture supernatants. The assay was set up as described above for IFN- $\gamma$ and TNF- $\alpha$. The concentrations of the standards 
used to generate the standard curve were $0,10.24,25.6,64,160$ and $400 \mathrm{pg} / \mathrm{ml}$. A standard curve for IL-4 was constructed as described above for TNF- $\alpha$, which was used to determine the concentration of IL-4 present in the test samples (culture supernatants), from the absorbance readings at $450 \mathrm{~nm}$ obtained for each test sample. All standards and test samples were run in duplicate, and the sensitivity of the test was $<2 \mathrm{pg} \mathrm{IL-4} / \mathrm{ml}$.

\section{Isolation of Leukocyte DNA}

Human PBL and PBMC fractions of leukocytes prepared by Protocols A and B respectively were cultured in 24 -well flat bottom tissue culture plates. Cell cultures were set up in duplicate. Each well contained $200 \mu \mathrm{l}$ of cell suspension $\left(1.5 \times 10^{6}\right.$ cells/well $)$, $100 \mu \mathrm{l}$ of growth medium and $50 \mu \mathrm{l}$ of test stimulant. Positive control cultures for apoptosis consisted of replacing the test stimulant (ASC) with $5 \mu \mathrm{M} / \mathrm{ml}$ of staurosporine or $5 \mu \mathrm{g} / \mathrm{ml}$ of camptothecin. The culture plates were incubated at $37^{\circ} \mathrm{C}$ for 4 hours, 8 hours, 24 hours and 48 hours in a humidified chamber with $5 \% \mathrm{CO}_{2}$. At each specified time point, cells were harvested by resuspending and aspirating the contents of each well into a sterile microcentrifuge tube. The DNA from test and control culture cells was isolated using the protocol described in the apoptotic DNA ladder kit (Roche Diagnostics Corporation, Indianapolis, $\mathbb{N}$ ). Cells undergoing apoptosis cleave their DNA into fragments of 180-200 bp and multiples of this unit length, a characteristic that can be visualized electrophorectically and used to identify apoptotic cells in a population. This type of cleavage appears as a ladder of DNA fragment bands on agarose electrophoresis gel. The DNA from the cultured PBMC treated with ASC was isolated following the kit manufacturer's instructions. DNA was examined for the appearance of a typical ladder of 
fragment bands on agarose gel electrophoresis. Briefly, PBMC cultures were set up as described above. Cultured cells were harvested and $200 \mu$ of cell suspension was mixed with $200 \mu$ of the binding buffer and incubated for 10 minutes at room temperature (20$25^{\circ} \mathrm{C}$ ). After incubation, $100 \mu \mathrm{l}$ of isopropanol was added to the mixture, which was vortexed for 30 seconds. A filter and a collection tube were combined to filter the ASC, staurosporine and camptothecin stimulated test samples, along with the positive control (apoptotic U937 cells) provided in the kit. The combined filter and collection tube set was centrifuged for one minute at $6,000 \times \mathrm{g}$. The filter tube contains glass fiber fleece to which nucleic acids bind specifically to the surface of glass fibers in the presence of chaotropic salts. The DNA immobilized on the filter was washed by passing $500 \mu$ of washing buffer twice through the fleece. Bound DNA was eluted with $200 \mu$ l of elution buffer and recovered by centrifugation at $6,000 \times \mathrm{g}$ for one minute into a sterile microcentrifuge tube. DNA concentration was calculated by diluting the sample 1:100 in water and reading the absorbance at $260 \mathrm{~nm}$. The concentration in $\mu \mathrm{g} / \mathrm{ml}$ was calculated by multiplying the absorbance at $260 \mathrm{~nm}$ by 50 . The purity was estimated by dividing the absorbance of the diluted sample at $260 \mathrm{~nm}$ by its absorbance at $280 \mathrm{~nm}$. This ratio is of 1.8 or higher for pure samples of DNA and a ratio lower than 1.8 reflects sample contamination with protein or phenol. DNA samples were stored at $-20^{\circ} \mathrm{C}$ until electrophoretic analysis in agarose gel electrophoresis was carried out.

\section{Electrophoretic Analysis of DNA}

A $1 \%$ agarose gel was prepared by mixing $0.5 \mathrm{~g}$ of agarose (Sigma Chemical Company, St. Louis, MO) with $50 \mathrm{ml}$ of $40 \mathrm{mM}$ Tris-Acetate containing $1 \mathrm{mM}$ EDTA, 
pH 8.3 (TAE Buffer Solution, Life Technologies, Rockville, MD). The agar mixture was heated until the agarose was completely dissolved. The mixture was cooled to $60^{\circ} \mathrm{C}$ and $0.5 \mu \mathrm{g} / \mathrm{ml}$ of ethidium bromide was added. The melted agarose medium was poured into a mounted electrophoresis chamber with the comb in place. The agarose gel was allowed to solidify. TAE electrophoresis buffer was added to the chamber to a level, which covered the agarose gel, the comb then was removed. Test samples and the positive control ( $3 \mu \mathrm{g}$ of purified DNA isolated from samples and control cells using the apoptotic DNA ladder kit) diluted 1 to 6 in loading buffer $(0.02 \%$ bromophenol blue, $40 \%$ glycerol in TBE [ $89 \mathrm{mM}$ Tris, $89 \mathrm{mM}$ boric acid, $2.5 \mathrm{mM}$ EDTA, $\mathrm{pH} 8.0]$ ) and loaded in to separate wells. A molecular size marker ( $\lambda$ DNA/Hind-III fragments, Life Technologies, Rockville, MD) was run as a reference control for size of electrophoretic fragments. Electrophoresis was carried out at 75 Volts for one hour at room temperature. The DNA bands were visualized by placing the gel onto an UV light source and results recorded by photographing the gel.

\section{Statistical Analysis}

Analysis of significance was performed using the Student's paired t-test whenever possible. Confidence limit of $95 \%$ was set to evaluate the data throughout this study. 


\section{Results}

\section{Shark Cartilage Extract}

An acid extract of shark cartilage (ASC) was prepared as described in Material and Methods. Protein concentration of the preparation was determined by the BCAprotein assay after the extract was dialyzed against $400 \mathrm{ml}$ of $0.02 \mathrm{M}$ Tris, $\mathrm{pH} 7.4$. A standard curve was generated using BSA standards (Figure 3), and the best points to produce a straight line were calculated by linear regression. The absorbance reading at $562 \mathrm{~nm}$ for the ASC preparation was plotted on the standard curve and the protein concentration determined. A protein concentration of $377 \mu \mathrm{g} / \mathrm{ml}$ was obtained (total protein of $13.2 \mathrm{mg}$ in $35 \mathrm{ml}$ ) for the preparation. This value is comparable to that (360 $\mu \mathrm{g} / \mathrm{ml}$ ) obtained by Simjee (Simjee, 1997) in an earlier study.

\section{Endotoxin Assay}

Each acid extract preparation of shark cartilage was tested for the presence of endotoxin before it was used to stimulate human leukocytes in vitro. The detection sensitivity for endotoxin of the E-Toxate test (Sigma Chemical Company, St. Louis, MO) range from 0.05 to $0.1 \mathrm{EU} / \mathrm{ml}$. Shark cartilage extract upon reaction with Limulus lysate remained as a clear liquid or soft gel on completion of the test indicating that the extract was free of any detectable endotoxin (Table 1). To eliminate the possibility of a negative reaction being due to the presence of an E-Toxate inhibitor in the ASC extract, $0.01 \mathrm{ml}$ of the $4 \mathrm{EU} / \mathrm{ml}$ endotoxin standard was added to a duplicate sample of extract and tested for the formation of a hard gel. The extract gave a positive reaction in this test. 


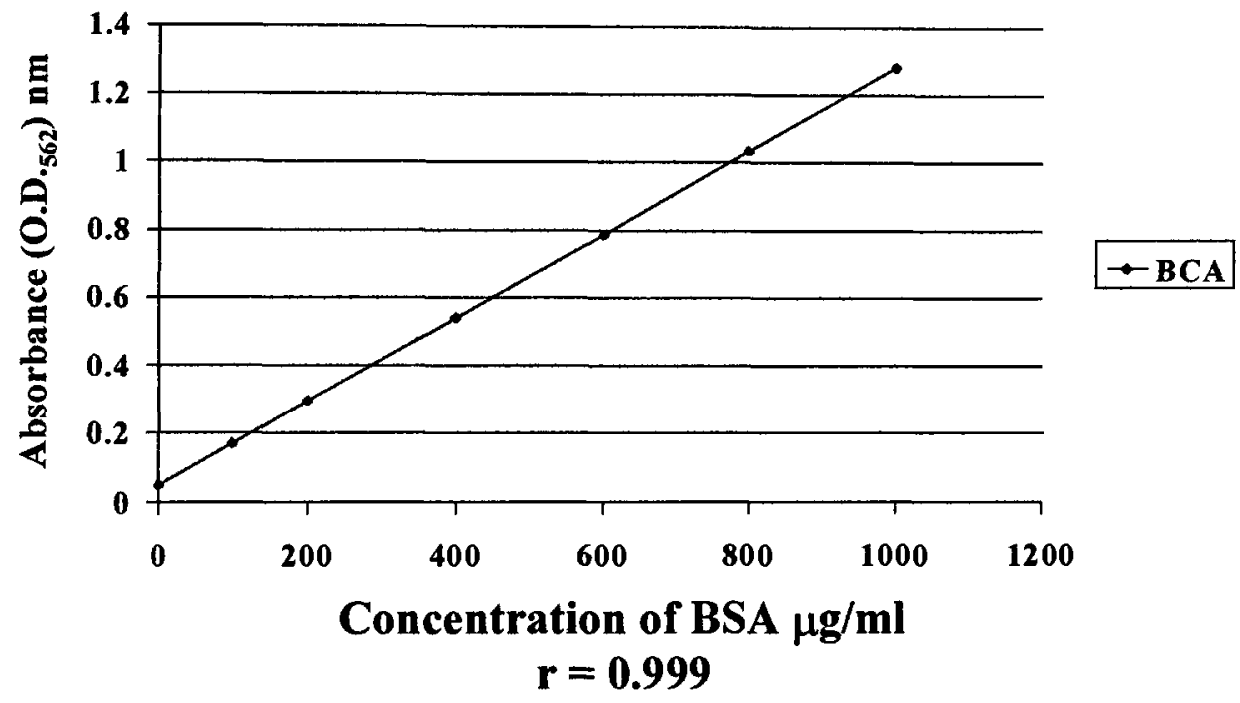

Figure 3: Protein standard curve. A standard curve was constructed with varying concentrations of bovine serum albumin (BSA) as protein standards. Linear regression was used to calculate the best points to produce a straight line on the standard curve. The BCA-protein assay was used to determine the protein concentration of shark cartilage extracts. The protein concentration was determined by plotting the absorbance readings at $562 \mathrm{~nm}$ for each sample on the standard curve. The protein concentration of the shark cartilage extract was $377 \mu \mathrm{g} / \mathrm{ml}$. 


\begin{tabular}{||l|c|c||}
\hline \multicolumn{1}{|c|}{ SAMPLE OR CONTROL } & REACTION* & $\begin{array}{c}\text { ENDOTOXIN (E) TEST } \\
\text { INTERPRETATION }\end{array}$ \\
\hline ASC & Soft gel & E absent \\
\hline $\begin{array}{l}\text { Test for E-Toxate inhibitor in ASC (sample } \\
\text { + standard } 4 \mathrm{EU} / \mathrm{ml} \text { ) }\end{array}$ & Hard gel & Absence of inhibitor \\
\hline Negative Control (endotoxin-free water) & Liquid & E absent \\
\hline Standard $0.5 \mathrm{EU} / \mathrm{ml}$ & Hard gel & E present \\
\hline Standard $0.25 \mathrm{EU} / \mathrm{ml}$ & Hard gel & E present \\
\hline Standard $0.125 \mathrm{EU} / \mathrm{ml}$ & Hard gel & E present \\
\hline Standard $0.06 \mathrm{EU} / \mathrm{ml}$ & Hard gel & E present \\
\hline Standard $0.03 \mathrm{EU} / \mathrm{ml}$ & Soft gel & E absent \\
\hline Standard $0.015 \mathrm{EU} / \mathrm{ml}$ & Liquid & E absent \\
\hline
\end{tabular}

* Sensitivity of the test: $0.05-0.1 \mathrm{EU} / \mathrm{ml}$

Table 1: Endotoxin assay. Acid extract of shark cartilage was assayied for the presence of endotoxin by employing E-Toxate kit. Reaction of each test sample and endotoxin standards, when mixed with Limulus amebocyte lysate was recorded. A hard gel formation represented a positive test for levels of endotoxin of $\geq 0.05 \mathrm{EU} / \mathrm{ml}$. All other degree of gelation, ranging from fluid to soft gels, indicated absence of endotoxin oe level $<0.05 \mathrm{EU} / \mathrm{ml}$.

\section{Comparison of Cell Separation Methods}

Three different methods of cell separation were performed as described in Material and Methods. Methods were compared with respect to the composition of the cell population obtained, the yield and the viability of the human leukocytes. Leukocytes from whole blood were separated by (a) Dextran sedimentation, or (b) Dextran sedimentation followed by density gradient centrifugation using Histopaque, or (c) density gradient centrifugation alone. Results are recorded in Table 2a and $b$ and Figure $4 \mathrm{a}, \mathrm{b}$ and $\mathrm{c}$. For each cell suspension isolated, a manual total cell count was performed and cell viability determined. To determine leukocyte yield, a total and differential count was determined for whole blood. Differential count for fractionated leukocyte populations was determined from cytospin monolayers of cells. When Dextran sedimentation by itself was used to harvest leukocytes, the cell suspension was 
heterogeneous and composed mostly of neutrophils with a high percentage of viable cells recovered (Figure 4A). When the suspension was further fractionated on a Histopaque gradient, a mononuclear cell fraction consisting primarily of lymphocytes with some monocytes was obtained, however, a lower percentage of viable cells were recovered (Figure 4b). Neutrophils were present in low numbers in this fraction. A mononuclear cell fraction separated on a Histopaque gradient directly from blood yielded a cell population of relatively high viability with significant yield from blood (Figure 4c). A higher percentage of monocytes was recovered with a similar small number of neutrophils remains in the fraction. The highest yield of total leukocytes was obtained with Dextran, mononuclear cells were separated equally well by either Histopaque alone or in combination with Dextran sedimentation. Protocols A and B were selected as method of choice to isolate leukocyte fractions enriched for neutrophils (PBL) and mononuclear cells (PBMC) respectively.

\section{Viability and Proliferation of Leukocyte in culture}

The viability and proliferation of cultured leukocytes grown in the absence of stimulants was measured at $0,4,24,30$ and 48 hours of incubation. Cultures were set up using a PBL fraction isolated by Protocol A, and PBMC fraction isolated by Protocol B. Cell viability was determined by the trypan blue exclusion test, while cell proliferation was measured by determining total cell counts manually. Results are recorded in Table 3 . Cell viability of PBL cultures decreased only slightly over 48 hours ( $98.5 \%$ to $94.4 \%$ ), with the PBMC culture viability being marginally less (96 to $94.5 \%$ ) over the same time period. 


\begin{tabular}{||l|c|c|c|c|c||}
\hline & $\begin{array}{c}\text { Total WBC } \\
\text { count in } \\
\text { whole blood } \\
(\text { cells/ml) } \varphi\end{array}$ & $\begin{array}{c}\text { Total WBC } \\
\text { Count in } \\
\text { separated cell } \\
\text { fraction* }\end{array}$ & $\begin{array}{c}\text { Total cell } \\
\text { viability } \\
(\%)\end{array}$ & $\begin{array}{c}\text { Total } \\
\text { WBC } \\
\text { yield } \\
(\%)\end{array}$ & $\begin{array}{c}\text { Mononuclear } \\
\text { cell yield } \\
(\%)\end{array}$ \\
\hline \hline $\begin{array}{l}\text { Dextran (PBL) } \\
\text { Protocol A }\end{array}$ & $5 \times 10^{6}$ & $\begin{array}{c}19.6 \times 10^{6} \\
(\mathrm{PBL})\end{array}$ & 97.5 & 78 & ND \\
\hline $\begin{array}{l}\text { Histopaque (PBMC) } \\
\text { Protocol B }\end{array}$ & $5 \times 10^{6}$ & $\begin{array}{c}3.7 \times 10^{6} \\
(\mathrm{PBMC})\end{array}$ & 94 & 30 & 82 \\
\hline $\begin{array}{l}\text { Dextran+Histopaque } \\
\text { (PBMC). Protocol C }\end{array}$ & $5 \times 10^{6}$ & $\begin{array}{c}2.7 \times 10^{6} \\
(\mathrm{PBMC})\end{array}$ & 93 & 27 & 83 \\
\hline
\end{tabular}

* Cells resuspended in $2 \mathrm{ml}$ of medium

$\varphi$ Whole blood WBC count: $5 \times 10^{6}$ cells $/ \mathrm{ml}$ containing $62 \%$ PMNs, $34 \%$ lymphocytes, $4 \%$ monocytes

ND: not done

a: Comparison of cell viability and leukocyte yield

\begin{tabular}{||l|c|c|c|c|}
\hline \multirow{2}{*}{} & \multicolumn{4}{|c||}{ Cytospin Film $^{\circ}$} \\
\cline { 2 - 5 } & \multicolumn{2}{|c|}{ Granulocytes } & \multicolumn{2}{c|}{ Mononuclear } \\
\cline { 2 - 5 } & $\begin{array}{c}\text { Neutrophils } \\
(\%)\end{array}$ & $\begin{array}{c}\text { Eosinophils } \\
(\%)\end{array}$ & $\begin{array}{c}\text { Lymphocytes } \\
(\%)\end{array}$ & $\begin{array}{c}\text { Monocytes } \\
(\%)\end{array}$ \\
\hline Dextran (PBL) & 73 & 3 & 17 & 7 \\
\hline Histopaque (PBMC) & 4 & 0 & 71 & 25 \\
\hline $\begin{array}{l}\text { Dextran+Histopaque } \\
\text { (PBMC) }\end{array}$ & 5 & 0 & 89 & 6 \\
\hline
\end{tabular}

${ }^{\infty} 200$ cells counted

$\varphi$ Whole blood WBC count: $5 \times 10^{6}$ cells/ml containing $62 \%$ PMNs, 34\% lymphocytes, $4 \%$ monocytes

b: Comparison of cell types in fractionated leukocyte populations.

Table 2: Analysis of leukocyte fractions. Leukocyte suspensions isolated from whole blood by dextran sedimentation (Protocol A), density gradient centrifugation on Histopaque (Protocol B) and a combination of both (Protocol C), were compared for cell viability and yield recovered (a), and composition and ratio of leukocyte types in the fractions (b). 


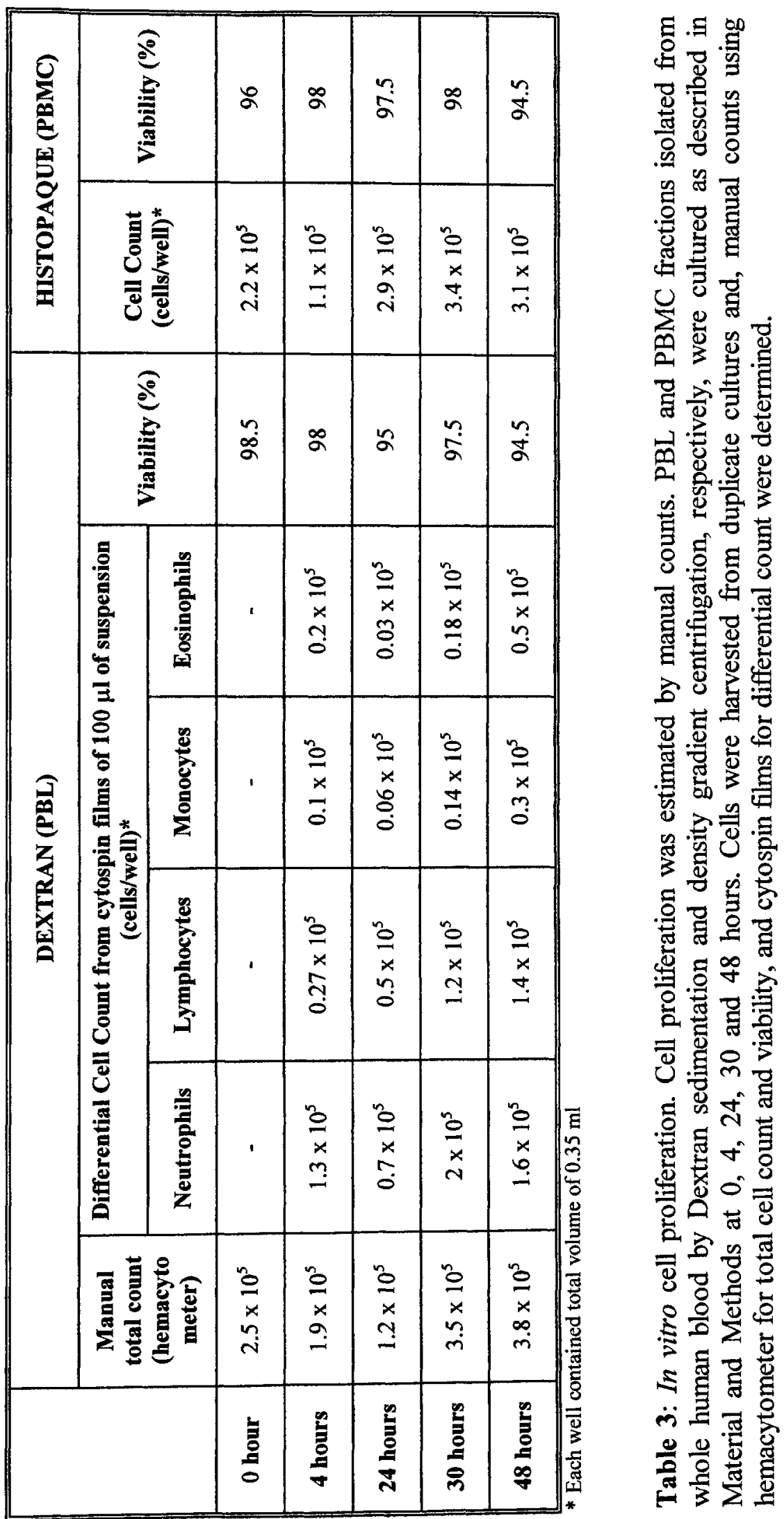


The pattern of proliferation of the two leukocyte cultures, determined by cell counts, however, differed significantly. PBL cell counts dropped significantly in the initial 24 hours and then total cell counts increased (Figure 5). The PBMC showed cell counts dropped (50\%) within 4 hours of culture, and then increased gradually over 48 hours (Figure 6).

\section{Morphology of Cultured Leukocytes}

The in vitro cell cultures of PBL and PBMC fractions of whole blood that were set up to assess proliferation were also examined for morphological changes of cell type at $4,20,24,30$ and 48 hours. Cell cultures were used to prepare cytospin monolayers for each sample, as described in the Material and Methods. Cytospin films were examined for morphology of the leukocytes. Leukocytes of both fractions of PBL and PBMC (Figure $7 \mathrm{a}$ and $\mathrm{b}$ ) in culture maintained normal morphology during the time periods tested. However, by 48 hours it was noted that in the PBL cultures some cells, mainly neutrophils, had a necrotic appearance while the majority of the PBL cells presented normal morphology as illustrated in Figure 7a.

\section{Effect of Shark Cartilage on in vitro Leukocyte Proliferation}

The effect of shark cartilage on the in vitro proliferation of PBMC fraction of leukocytes was measured using the MTT assay as described in the Material and Methods. PBMC cell cultures grown in the presence of ASC showed the same proliferation rate as these grown in the absence of ASC (Table 4), indicating that shark cartilage did not inhibit normal cell proliferation under our experimental conditions. 
Compared to cultures stimulated with ASC and in the absence of stimulant (control), PBMC cultures stimulated with the mitogen LPS or ConA showed a rate and level of cell proliferation over time, which statistically was not significantly different from that of control cultures and ASC stimulated cultures. The lack of difference in the proliferative response between the cultures was unexpected as ConA and LPS are mitogens known to induce significant proliferative response and under our experimental conditions did not do so. Thus, from results we can only say that ASC has no inhibitory effect (as cells grew similar to control) but an ability for up regulation can not be ruled out.

\begin{tabular}{|c|c|c|c|c|c|c|}
\hline & \multicolumn{3}{|c|}{ ASC } & \multicolumn{3}{|c|}{ Unstimulated Control } \\
\hline & 4 hours & 24 hours & 48 hours & 4 hours & 24 hours & 48 hours \\
\hline Mean O.D. $570-630 \mathrm{~nm}$ & 0.166 & 0.236 & 0.314 & 0.0 .161 & 0.0 .234 & 0.0 .316 \\
\hline Pooled t value* & \multicolumn{3}{|c|}{0.05} & \multicolumn{3}{|c|}{ - } \\
\hline$p$ value & \multicolumn{3}{|c|}{$p>0.05$} & \multicolumn{3}{|c|}{ - } \\
\hline \multirow[t]{3}{*}{ Standard Error } & \multicolumn{3}{|c|}{0.04} & \multicolumn{3}{|c|}{ - } \\
\hline & \multicolumn{3}{|c|}{ LPS } & \multicolumn{3}{|c|}{ ConA } \\
\hline & 4 hours & 24 hours & 48 hours & 4 hours & 24 hours & 48 hours \\
\hline Mean O.D.570-630 nm & 0.145 & 0.185 & 0.209 & 0.148 & 0.212 & 0.233 \\
\hline Pooled t value* & \multicolumn{3}{|c|}{1.15} & \multicolumn{3}{|c|}{1.08} \\
\hline$p$ value & \multicolumn{3}{|c|}{$p>0.05$} & \multicolumn{3}{|c|}{$\mathrm{p}>0.05$} \\
\hline Standard Error & \multicolumn{3}{|c|}{0.02} & \multicolumn{3}{|c|}{0.03} \\
\hline
\end{tabular}

$* t$ value calculated using pooled-t test comparing ASC, LPS and ConA to unstimulated control

Table 4: Cell proliferation measured by MTT assay. Relative increase of in vitro proliferation of human leukocytes (PBMC) cultured in triplicate for 48 hours in the presence of ASC, LPS and ConA, or in the absence of any stimulant. Cultures were seeded with $1.8 \times 10^{5}$ cells/well. Proliferation was determined by the MTT assay, which measures the amount of reduced formazan by reading the absorbance of each sample (triplicate readings of O.D.) at $570 \mathrm{~nm}$ with a reference filter of $630 \mathrm{~nm}$. 


\section{TNF- $\alpha$ Secretion by Shark Cartilage-Stimulated Leukocytes}

Levels of free TNF- $\alpha$ in culture supernatants were measured by ELISA, as described in Material and Methods. Standard curves were generated using the TNF- $\alpha$ standards, and the best points to give a straight line were calculated by linear regression (Figure 8). When PBL fraction $\left(2.4 \times 10^{5}\right.$ cells/well) was cultured and stimulated with ASC extract significant levels $(p<0.05)$ of TNF- $\alpha$ was secreted in the culture supernatants at 4 and 8 hours of stimulation (Table 5), when compared to unstimulated culture controls. At 20 hours, however, no free TNF- $\alpha$ could be detected in ASC culture supernatants, whereas corresponding cultures stimulated with LPS showed high levels of TNF- $\alpha$ at 20 hours with levels falling by 48 hours (Figure 9). The pattern of TNF- $\alpha$ secretion by cultured PBMC $\left(2.2 \times 10^{5}\right.$ cells/well $)$ stimulated with ASC extract was different. The levels of TNF- $\alpha$ increased gradually over time reaching a peak at 20 hours. Significant levels $(\mathrm{p}<0.05)$ of TNF- $\alpha$ was secreted and detected in culture supernatants up to 48 hours, similar to TNF- $\alpha$ secretion by LPS-stimulated cultures (Table 6). No free TNF- $\alpha$ was detected in supernatants of unstimulated cultures (Figure 10). The difference in TNF- $\alpha$ secretion by the two types of cell culture (PBL and PBMC) can be explained by the composition and cell type (relative numbers of mononuclear cells) present. It should be noted that while TNF- $\alpha$ is a cytokine produced by a variety of cell types, the primary source of this cytokine is monocytes/macrophages. 


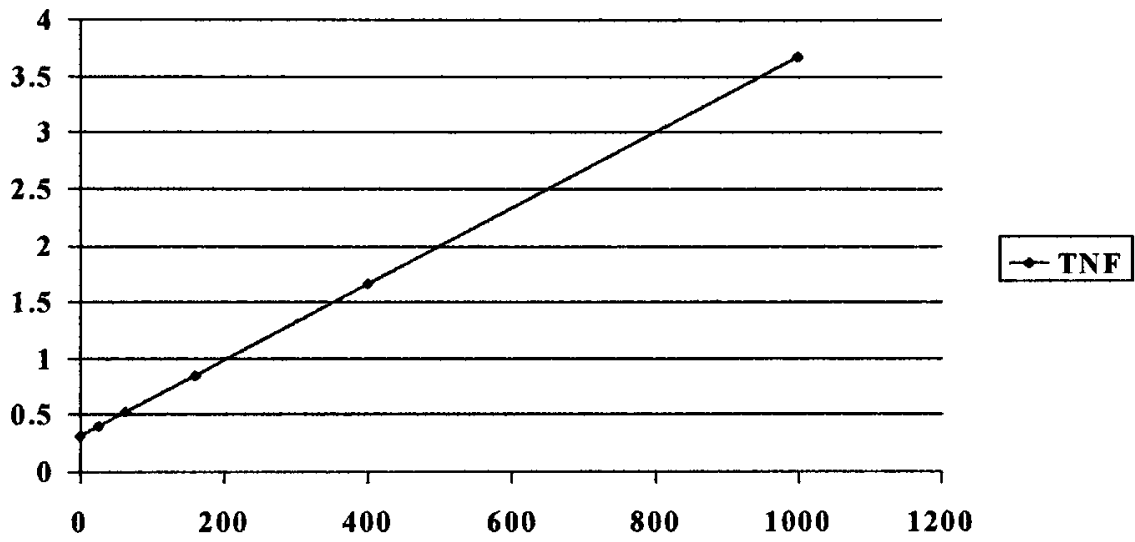

Concentration of TNF- $\alpha \mathrm{pg} / \mathrm{ml}$

$$
r=0.974
$$

Figure 8: TNF- $\alpha$ standard curve. A standard curve was constructed using varying concentrations of TNF- $\alpha$ standards. Linear regression was used to calculate the best points to produce a straight line on the standard curve. This was used to determine the concentration of free TNF- $\alpha$ present in supernatants of PBL and PBMC cultures. TNF- $\alpha$ concentration was determined by plotting the average absorbance reading at $450 \mathrm{~nm}$ obtained for each sample on the standard curve and reading the corresponding concentration of TNF- $\alpha$. 


\begin{tabular}{|c|c|c|c|c|c|}
\hline & \multicolumn{5}{|c|}{ 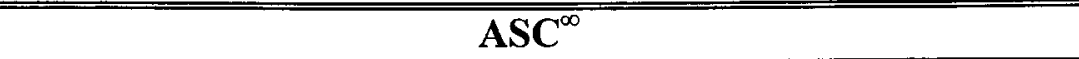 } \\
\hline & 4 hours & 8 hours & 20 hours & 24 hours & 48 hours \\
\hline Mean O.D.450 nm & 0.377 & 0.393 & 0.239 & 0.197 & 0.080 \\
\hline TNF $-\alpha(\mathrm{pg} / \mathrm{ml})$ & 18.07 & 22.5 & 0 & 0 & 0 \\
\hline Paired t value & 30.6 & 45 & - & - & - \\
\hline p value & $<0.05$ & $<0.05$ & - & - & - \\
\hline Standard error & 0.6 & 0.5 & - & - & - \\
\hline \multirow[t]{3}{*}{$\mathrm{CI}^{*}$} & $14-22$ & $19-26$ & - & - & - \\
\hline & \multicolumn{5}{|c|}{ LPS $^{\infty}$} \\
\hline & 4 hours & 8 hours & 20 hours & 24 hours & 48 hours \\
\hline Mean O.D.450 nm & 0.728 & 1.201 & 1.345 & 1.242 & 0.438 \\
\hline TNF- $\alpha(\mathrm{pg} / \mathrm{ml})$ & 123 & 263 & 305 & 275 & 63 \\
\hline Paired t value & 245 & 175 & 9.5 & 11 & 125 \\
\hline p value & $<0.05$ & $<0.05$ & $<0.05$ & $<0.05$ & $<0.05$ \\
\hline Standard error & 0.5 & 1.5 & 32 & 25 & 0.5 \\
\hline \multirow[t]{3}{*}{$\mathrm{CI}^{*}$} & $119-126$ & $253-272$ & $103-507$ & $117-433$ & $134-206$ \\
\hline & \multicolumn{5}{|c|}{ Unstimulated Control } \\
\hline & 4 hours & 8 hours & 20 hours & 24 hours & 48 hours \\
\hline Mean O.D.450 nm & 0.072 & 0.085 & 0.080 & 0.079 & 0.072 \\
\hline TNF- $\alpha(\mathrm{pg} / \mathrm{ml})$ & 0 & 0 & 0 & 0 & 0 \\
\hline
\end{tabular}

* Confidence Interval

${ }^{\infty}$ Parameters were calculated from duplicate samples

Table 5: Production of TNF- $\alpha$ by PBL cultures. Levels of free TNF- $\alpha$ present in PBL culture supernatants. Cell cultures initially contained $2.4 \times 10^{5}$ cells/well. 


\begin{tabular}{|c|c|c|c|c|c|}
\hline & \multicolumn{5}{|c|}{$\mathbf{A S C}^{\infty}$} \\
\hline & 4 hours & 8 hours & 20 hours & 24 hours & 48 hours \\
\hline Mean O.D.450 nm & 0.973 & 1.001 & 1.568 & 1.324 & 0.480 \\
\hline TNF- $\alpha(\mathrm{pg} / \mathrm{ml})$ & 195 & 204 & 372 & 300 & 49 \\
\hline Paired t value & 32.5 & 81.4 & 5.8 & 46 & 97 \\
\hline p value & $<0.05$ & $<0.05$ & $<0.05$ & $<0.05$ & $<0.05$ \\
\hline Standard error & 6 & 2.5 & 64.5 & 6.5 & 0.5 \\
\hline \multirow[t]{3}{*}{$\mathbf{C I}^{*}$} & $157-233$ & $188-219$ & $-36-779$ & $258-341$ & $45-52$ \\
\hline & \multicolumn{5}{|c|}{ LPS $^{\infty}$} \\
\hline & 4 hours & 8 hours & 20 hours & 24 hours & 48 hours \\
\hline Mean O.D.450 nm & 0.902 & 1.949 & 1.950 & 1.921 & 0.908 \\
\hline TNF- $\alpha(\mathrm{pg} / \mathrm{ml})$ & 174 & 485 & 485 & 476 & 176 \\
\hline Paired t value & 58 & 57 & 7.8 & 3174 & 117 \\
\hline p value & $<0.05$ & $<0.05$ & $<0.05$ & $<0.05$ & $<0.05$ \\
\hline Standard error & 3 & 8.5 & 62 & 0.2 & 1.5 \\
\hline \multirow[t]{3}{*}{$\mathrm{CI}^{*}$} & $155-193$ & $431-538$ & $94-876$ & $475-477$ & $166-185$ \\
\hline & \multicolumn{5}{|c|}{ Unstimulated Control } \\
\hline & 4 hours & 8 hours & 20 hours & 24 hours & 48 hours \\
\hline Mean O.D.450 nm & 0.068 & 0.078 & 0.09 & 0.078 & 0.073 \\
\hline TNF- $\alpha(\mathrm{pg} / \mathrm{ml})$ & 0 & 0 & 0 & 0 & 0 \\
\hline
\end{tabular}

* Confidence Interval

${ }^{\infty}$ Parameters were calculated from duplicate samples

Table 6: Production of TNF- $\alpha$ by PBMC cultures. Levels of free TNF- $\alpha$ present in PBMC culture supernatants. Cell cultures initially contained $2.2 \times 10^{5}$ cells/well. 


\section{IFN- $\gamma$ Secretion by Shark Cartilage-Stimulated Leukocytes}

Culture supernatants from PBMC $\left(1.36 \times 10^{6}\right.$ cells/well $)$ were tested for the presence of IFN- $\gamma$. The solid-phase ELISA used for this purpose is described in Material and Methods, and the standard curve generated from IFN- $\gamma$ standards is shown in Figure 11. IFN- $\gamma$ was not detected in ASC-stimulated or unstimulated control culture supernatants at any time period of stimulation. Supernatants from cell cultures stimulated with LPS (positive controls) contained significant levels $(\mathrm{p}<0.05)$ of IFN $-\gamma$ at $20,24,30$ and 48 hours (Figure 12). It should be noted, however, that IFN- $\gamma$ was not detected at 4 hours in supernatants of the LPS-stimulated cultures. Furthermore, cultures for IFN- $\gamma$ production were seeded with more cells/well $\left(1.36 \times 10^{6}\right)$ than cultures for TNF- $\alpha$ production $\left(2.2 \times 10^{5}\right)$.

\section{IL-4 Secretion by Shark Cartilage-Stimulated Leukocytes}

The level of IL-4 in supernatants of PBMC cultures was determined by ELISA. Cultures using two different cell densities $\left(2.2 \times 10^{5}\right.$ cells/well and $1.36 \times 10^{6}$ cells/well $)$ were set up. The standard curve used to determine the level of IL-4 in PBMC ( $2.2 \times 10^{5}$ cells/well) supernatants is shown in Figure 13. The level of IL-4 detected in culture supernatants of PBMC stimulated with ASC extract was not statistically significant at any of the time periods tested (Figure 14) from levels obtained for unstimulated control culture. There was also no significant difference when compared to IL-4 levels produced by ConA-stimulated cultures at 20,24 and 48 hours. Furthermore, in cell cultures of PBMC seeded with $2.2 \times 10^{5}$ cells/well, there was no detectable IL-4 in the supernatants stimulated with PMA at any time period. 


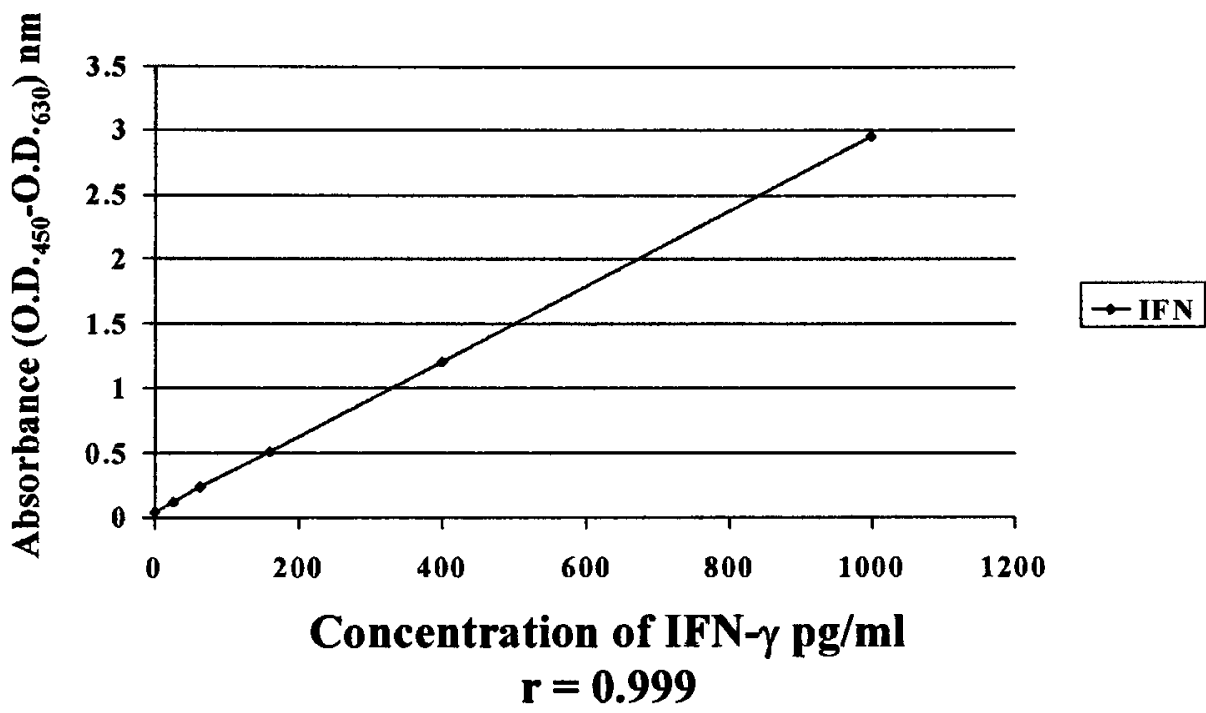

Figure 11: IFN- $\gamma$ standard curve. A standard curve was constructed using varying concentrations of IFN- $\gamma$ standards. Linear regression was used to calculate the best points to produce a straight line on the standard curve. This was used to determine the concentration of free IFN- $\gamma$ present in supernatants of PBMC cultures. IFN- $\gamma$ concentration was determined by plotting the average absorbance reading at $450 \mathrm{~nm}$ obtained for each sample on the standard curve and reading the corresponding concentration of IFN- $\gamma$. 


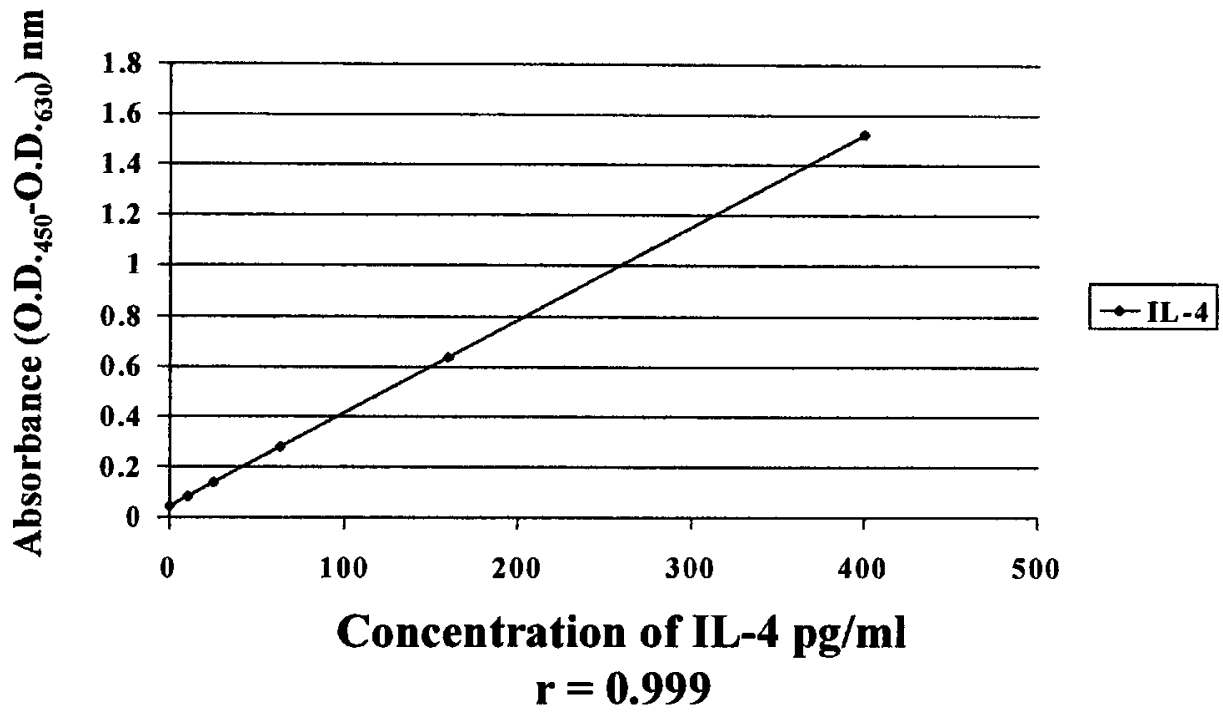

Figure 13: IL-4 standard curve. A standard curve was constructed using varying concentrations of IL-4 standards. Linear regression was used to calculate the best points to produce a straight line on the standard curve. This was used to determine the concentration of free IL-4 present in supernatants of PBMC cultures $\left(2.2 \times 10^{5}\right.$ cells/well). IL-4 concentration was determined by plotting the average absorbance reading at $450 \mathrm{~nm}$ obtained for each sample on the standard curve and reading the corresponding concentration of IL-4. 


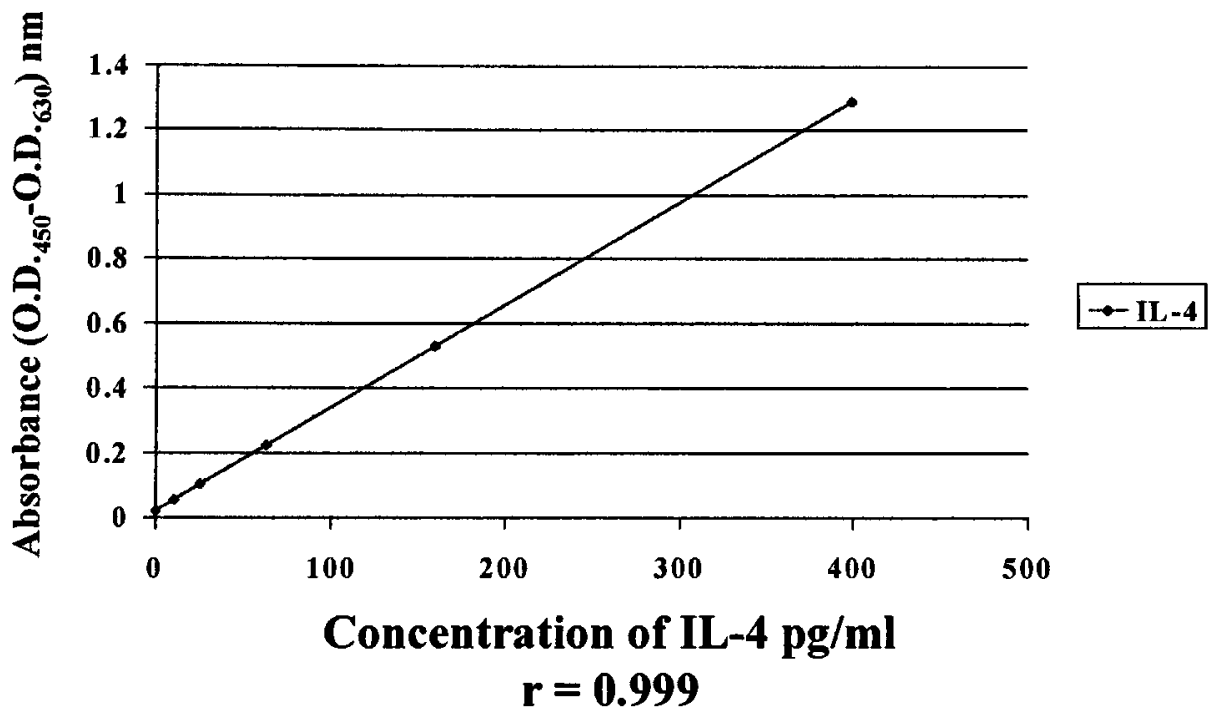

Figure 15: IL-4 standard curve. A standard curve was constructed using varying concentrations of IL-4 standards. Linear regression was used to calculate the best points to produce a straight line on the standard curve. This was used to determine the concentration of free IL-4 present in supernatants of PBMC cultures $\left(1.36 \times 10^{6}\right.$ cells/well). IL-4 concentration was determined by plotting the average absorbance reading at $450 \mathrm{~nm}$ obtained for each sample on the standard curve and reading the corresponding concentration of IL-4. 
In an attempt to increase detection of significant levels of IL-4 in the supernatants cell cultures were set up seeded with an increased number of PBMC. Cultures seeded with $1.36 \times 10^{6}$ cells/well were stimulated with ASC extract and supernatants for assayed IL-4. The standard curve constructed for this assay is shown in Figure 15. Again, there was no detectable free IL-4 in the supernatants stimulated with ASC extract (Figure 16), however, significant levels $(\mathrm{p}<0.05)$ of IL-4 were detected in supernatants from cultures stimulated with Con A, which peaked at 20 hours and gradually declined thereafter. Unstimulated cell cultures produced no detectable IL-4 in culture supernatants.

\section{Apoptosis in ASC Stimulated Leukocyte Cultures}

\section{Morphological Assessment}

Cytospin monolayers of PBL cultures were prepared as described in the Material and Methods, and examined for the typical morphological changes that are characteristic of leukocytes undergoing apoptosis. PBL $\left(1.7 \times 10^{6}\right.$ cells/well $)$ were cultured for four hours in the presence of ASC extract, or different concentrations $(0.5,1.0,5.0$ and 10 $\mu \mathrm{M} / \mathrm{ml}$ ) of staurosporine, which was used as an inducer of apoptosis. Results are recorded in Table 7. Morphological changes typical of apoptosis, such as reduction in cell volume, nuclei shrinkage and nuclear fragmentation were observed in some cells present in the cytospin preparations. A statistically significant difference was noted in the number of apoptotic cells present in ASC-stimulated cultures and the number observed in the unstimulated control culture. Furthermore, no statistically significant difference was noted in the number of apoptotic cells present in cartilage-stimulated leukocyte cultures and those stimulated with $0.5 \mu \mathrm{M} / \mathrm{ml}$ of staurosporine. At four concentrations tested, staurosporine induced significant apoptosis in PBL cultures when compared to the 
unstimulated culture control. The percentage of apoptotic cells present in staurosporinestimulated cultures at 4 hours was similar (25-29\%) for staurosporine concentrations ranging from $1.0 \mu \mathrm{M} / \mathrm{ml}$ up to $10 \mu \mathrm{M} / \mathrm{ml}$. The apoptotic changes noted in PBL cultures at 4 hours are illustrated in Figure 17.

\begin{tabular}{|l|c|c|c|}
\hline $\begin{array}{l}\text { SAMPLES AND } \\
\text { CONTROLS }\end{array}$ & $\begin{array}{c}\text { APOPTOTIC } \\
\text { CELLS (\%) }\end{array}$ & t value & Standard Error \\
\hline Unstimulated Control $\mathbf{l}^{\infty}$ & 2.4 & - & 0.52 \\
\hline Staurosporine $(\mathbf{0 . 5} \mu \mathbf{M} / \mathbf{m l})^{\infty}$ & 7.4 & 3.57 & 0.94 \\
\hline Staurosporine $(\mathbf{1} \boldsymbol{M} \mathbf{m} \mathbf{m l})$ & 27 & ND & ND \\
\hline Staurosporine $(\mathbf{5} \mu \mathbf{M} / \mathbf{m l})$ & 25 & ND & ND \\
\hline Staurosporine $(\mathbf{1 0} \mu \mathbf{M} / \mathbf{m l})$ & 29 & ND & ND \\
\hline Stimulated with $\mathbf{A S C}$ & 6.2 & 4.34 & 0.81 \\
\hline
\end{tabular}

ND: not done

* Total of 100 PBL were counted to calculate the percentage of viable and apoptotic cells.

${ }^{\infty}$ Difference between Staurosporine $0.5 \mu \mathrm{M} / \mathrm{ml}$ and ASC-stimulated cultures is not statistically significant $(\mathrm{p}>0.05)$; however, between them and the unstimulated control culture is significant $(p<0.05)$.

Table 7 Apoptotic cells in PBL cultures. The relative number of apoptotic cells present in leukocyte populations $\left(2.4 \times 10^{5} \mathrm{PBL} /\right.$ well $)$ when cultured in vitro for 4 hours at $37^{\circ} \mathrm{C}$ in the presence of shark cartilage extract (ASC) or different concentrations of staurosporine $(0.5-10 \mu \mathrm{M} / \mathrm{ml})$. Unstimulated control cultures were grown in medium alone.

PBMC (1.63 x $10^{6}$ cells/well) were cultured for 24 hours in medium alone, in the presence of shark cartilage, staurosporine $(5 \mu \mathrm{M} / \mathrm{ml})$ or camptothecin $(5 \mu \mathrm{g} / \mathrm{ml})$. The latter were used to induce apoptosis. Cytospin monolayers were prepared and microscopically examined for cells showing typical apoptotic changes in the form of cytoplasmic constriction, blebbing, chromatin condensation and nuclear fragmentation. Results are recorded in Table 8 and illustrated in Figure 18. The few apoptotic cells observed in the cytospin preparation of unstimulate cultures is to be expected. 


\begin{tabular}{||l|c|}
\hline \hline SAMPLES AND CONTROLS & APOPTOTIC CELLS (\%) \\
\hline Negative Control & 2 \\
\hline Staurosporine $(5 \mu \mathrm{M} / \mathrm{ml})$ & 24 \\
\hline Camptothecin $(5 \mu \mathrm{g} / \mathrm{ml})$ & 11 \\
\hline ASC & 6 \\
\hline
\end{tabular}

Total of 100 PBMC were counted to calculate the percentage of viable and apoptotic cells.

Table 8 Apoptotic cells in PBMC cultures. The relative number of apoptotic cells present in leukocyte populations (1.63 x $10^{6} \mathrm{PBMC} /$ well $)$ when cultured in vitro for 24 hours at $37^{\circ} \mathrm{C}$ in the presence of shark cartilage extract (ASC) or staurosporine $(5 \mu \mathrm{M} / \mathrm{ml})$ and camptothecin $(5 \mu \mathrm{g} / \mathrm{ml})$. Unstimulated control cultures were grown in medium alone.

\section{Assessment by DNA Fragmentation Pattern}

DNA from PBMC cultures stimulated with ASC extract for 4, 8, 24 and 48 hours was isolated using the Apoptotic DNA Ladder kit, as described in the Material and Methods. Eletrophoretic analysis in agarose gel was performed to observe DNA fragmentation, which when present has the appearance of a typical apoptotic ladder formation exhibited by DNA extracted from U937 cells provided in the kit as a DNA fragmented control (Figure 19, lane 2). Staurosporine $(5 \mu \mathrm{M} / \mathrm{ml})$ and camptothecin $(5 \mu \mathrm{g} / \mathrm{ml})$ stimulated cell cultures were set up as positive culture controls for the cell population under study (PBMC). DNA ladder formation was not observed in DNA obtained from unstimulated, ASC-stimulated cultures or cultures treated with either staurosporine or camptothecin and incubated for 8 hours (Figure 19 a, lanes 1, 3, 4, 5 and 6 respectively). The typical DNA ladder formation could only be observed with DNA extracted from the apoptotic cells provided as a control (Figure 19a, lane 2).

A hind III digest of $\lambda$ DNA was run as molecular size marker (lane 7). At 24 hours, evidence for typical DNA ladder formation could not be seen for ASC, staurosporine and camptothecin stimulated cultures (Figure 19b, lanes 1, 3 and 4). 
However, these appeared to be a reduction in the brightness/intensity of the starting material DNA band (when compared to DNA from earlier cultures) indicating some loss of high molecular size DNA. At 48 hours, a significant decrease in the staining intensity of sample DNA from ASC and staurosporine stimulated cultures (Figure 19b, lane 6 and 7 respectively) was noted, along with presence of faint bands of lower molecular size DNA (i.e. fragments), particularly for the staurosporine stimulated culture. A decrease in the amount of sample DNA from unstimulated culture was also noted, however, it was significantly less (Figure 19b, lane 5). This was to be expected given (a) unstimulated cells normally undergo apoptosis, and (b) morphological examination of cytospin monolayers of unstimulated cultures had shown presence of a few apoptotic cells. 


\section{Discussion}

Shark cartilage, available commercially as a food supplement, is classified by the NCCAM as a biological-based therapeutic substance under the practice of Alternative Medicine. Shark cartilage is not only used as a therapeutic agent for the treatment of rheumatoid arthritis, psoriasis, scleroderma, AIDS, and certain cancers, but also for prophylactic purposes by healthy individuals. The therapeutic and prophylactic use of shark cartilage is increasing among the general population, even though its effectiveness has not been definitively proven. Shark cartilage, however, has been shown to inhibit angiogenesis (Berbari et al., 1999), modulate the immune system (Fontenele et al., 1997 and serve as a scavenger of oxygen reactive species (Felzenszwalb et al., 1998). The focus of most shark cartilage studies is on its use as an angiogenesis inhibitor. Little is known about its short and long term effects on the immune system of healthy individuals, particularly on leukocyte function.

Previous studies showed that different preparations of shark cartilage extracts (acid, salt-soluble and phosphate-buffered saline extracts), stimulated human leukocytes in vitro to release significant levels of TNF- $\alpha$ after 24 and 48 hours of incubation, with the highest cytokine response obtained with the acid extract (Simjee, 1997; Simjee and Smith, 1997). This earlier study had also shown that the "active" component in the extracts was susceptible to digestion with proteolytic enzymes, suggesting it to be proteinaceous in nature. To study further the in vitro effect of shark cartilage on human leukocytes, we investigated the production and release of IL-4 and INF- $\gamma$ by leukocytes following stimulation with acid extract of shark cartilage. Furthermore, the present study 
also undertook to examine treated cells for evidence of apoptosis and a proliferative response.

The ASC reagent prepared for this study had a protein concentration similar to that of the ASC preparation used in the previous study. The shark cartilage extract was tested for endotoxin before it was used to stimulate leukocytes in vitro. This was done to rule out the possibility of the cellular response being due to contaminating endotoxin present in the ASC preparation. The ASC reagent was determined to be relatively free of endotoxin using the E-Toxate kit, which detects endotoxinn levels as low as $0.05 \mathrm{EU} / \mathrm{ml}$, a level considered to be lower than the threshold required to stimulate cells. We are reasonably certain (considering the results obtained from our control culture) that the effects of stimulation noted are due directly to ASC and not from the presence of endotoxin contaminating the preparation.

Cell suspensions for in vitro culture were prepared by two different methods of cell separation: Dextran sedimentation, which produced a heterogeneous population of leukocytes rich in polymorphonuclear neutrophils (PMNs), and density gradient centrifugation (using Histopaque), which yielded a leukocyte fraction rich in mononuclear cells. We decided to use two different cell fractions in order to maximize our experimental conditions to include optimal cell types required to produce detectable levels of cytokines in culture supernatants. When stimulated with LPS, TNF- $\alpha$ is primarily produced by mononuclear cells. However, it is also produced by many other cell types such as neutrophils and NK cells which makes it reasonable to use both PBL or PBMC fractions to determine if anyone population (enriched for a certain cell type) showed enhanced response to LPS or other stimulant. IFN- $\gamma$ and IL-4 are cytokines 
produced by more restricted cell populations. IL-4 is almost exclusively produced by T cells and IFN- $\gamma$ by T cells and NK cells, making culture of PBMC fraction more suitable for the study of these cytokines.

The in vitro cell proliferation and viability were evaluated by performing manual cell counts in parallel with cell culture for cytokine production in order to confirm that the cells were able to grow in our system. Initially viability tests on the cells in culture showed them to be dying after a few hours of incubation, which was believed to be due to insufficient $\mathrm{CO}_{2}$ present in the growth chamber. Once cultures were maintained in a $\mathrm{CO}_{2}$ incubator with constant level of gas and humidity, the growth of leukocytes for longer periods was achieved as seen by the increase in cell numbers determined by manual cell count. The approximate number of cells in a cell suspension can be estimated by a manual cell count. While this method is not as accurate method as flow cytometry, for the purpose of our study this method was valuable to determine cell proliferation in the cultures and to confirm that the leukocytes in culture were viable and able to proliferate under our experimental conditions. In cultured PBL fraction, the number of PMNs in the harvested cells dropped within the first 24 hours and then there was an apparent increase in number seen at 48 hours. On the other hand, the number of lymphocytes continued to increase gradually over 48 hours, reaching numbers similar to PMNs, which originally was the predominant cell type in this fraction. In the corresponding cytospin monolayers of this fraction, this change of predominance in cell type was confirmed. There are two possible explanations for the observations noted. First, PMNs being terminal cells might well be expected to die, and are being substituted by proliferating mononuclear cells, thus maintaining total cell numbers. Secondly, PMNs could be sticking firmly to the bottom 
surface of the cell culture wells and not being "harvested". The latter is probably the more reasonable explanation due to the fact that the cell viability was high, implying that cells were not dying in the culture. The apparent increase, proportionately of PMNs in later culture might be that older cells are easily dislodged.

Along with cell viability and proliferation, cell morphology was evaluated by cytochemical analysis using cytospin monolayers obtained from cell suspensions harvested from untreated cultures, to reaffirm that our experimental conditions were optimal for cell maintenance and growth. As shown in Results, PBL and PBMC cell cultures had normal morphology indicating that the cells were viable and metabolically capable. The MTT assay is a more accurate method to evaluate cell proliferation than manual cell counts, as it is a colorimetric assay that measures the amount of formazan reduced by viable cells. The amount, therefore, of formazan reduced is directly proportional to the number of viable/metabolizing cells in culture. This method was selected to evaluate the effect of shark cartilage on leukocyte proliferation. Under our experimental conditions, in vitro leukocyte proliferation, measured by the MTT assay, was not inhibited by shark cartilage, when proliferation was compared to that obtained with unstimulated cultures. Unexpectly however, cell proliferation was not enhanced in the presence of mitogens LPS and ConA, which are typically used to induce increased cell proliferation.

Culture of PBL was set up to confirm that under our experimental conditions TNF- $\alpha$ could be induced by our preparations of ASC similar to the results obtained previously in our laboratory. This was the case, however, the pattern of cytokine production (biphasic) was not seen. Cultured PBMC were stimulated with ASC to 
determine whether the type of cell influenced the cellular response (i.e. TNF- $\alpha$ secretion) to ASC. Like previous studies, PBL when stimulated with ASC, produced TNF- $\alpha$, however, the biphasic response noted in earlier studies where TNF- $\alpha$ levels peaked at 8 and 24 hours with a drop at 12 hours was not noted. Under our experimental conditions, the level of TNF- $\alpha$ peaked at 20 hours with no drop being noted before a peak. It should be noted, however, that in this study culture supernatants were not assayed for TNF- $\alpha$ at 12 hours, and it is possible that during the 12-hour period, levels did drop but could not be noticed. PBMC cultures were stimulated with ASC (and LPS and ConA) to detect IL4 and IFN- $\gamma$ production, as IL-4 and INF- $\gamma$ are cytokines produced by $\mathrm{T}$ cells primarily. PBMC fraction is a mononuclear cell enriched preparation and contains primarily lymphocytes.

The pattern of cytokine production obtained in our study was different from the one obtained previously. We detected TNF- $\alpha$ in culture supernatants up to 8 hours after stimulation with ASC when PBL was used, as opposed to Simjee and Smith, who detected this cytokine up to 30 hours after stimulation with acid shark cartilage extract. The different pattern obtained in the two studies could be explained by (a) differences in the composition of the ASC extract, considering that these are crude extracts and might have differences in their components, stimulating cells to produce cytokines at different levels, (b) different responding cells, considering individual differences in cytokine production by different subjects who donated cells for the two studies and (c) difference in the PBL fraction composition, which could be richer in mononuclear cells in the earlier study compared to ours, which was mostly composed by PMNs. We also compared TNF- 
$\alpha$ response by ASC-stimulated PBMC. With this cell population, we detected high levels of TNF- $\alpha$ in the culture supernatants stimulated with ASC and LPS up to 48 hours of incubation. This result can be readily explained by the difference in cell population between PBL and PBMC. TNF- $\alpha$ is a cytokine produced primarily by mononuclear cells, which are present in higher concentration in the PBMC preparation. The concentration in $\mathrm{pg} / \mathrm{ml}$ of TNF- $\alpha$ obtained in culture supernatants from both PBL and PBMC stimulated with either ASC or LPS during this study was lower for all time periods than the concentration obtained in the previous study of both stimulants. This could be explained the fact that as we did not detect TNF- $\alpha$ after 8 hours in the PBL fraction like previously, there was an extended lag period.

We decided to test for IL-4 production by ASC-stimulated PBMC because, unlike TNF- $\alpha$, IL- 4 is a cytokine that is characteristic of the development of Th- 2 type of immune response, which in turn leads to the development of an anti-inflammatory response with concomitant production of antibodies. Conversely, TNF- $\alpha$ is a Th-1 type of cytokine that leads to the development of an inflammatory response after antigen stimulation, with the presence of cytotoxicity and development of delayed-type hipersensitivity. We were unable to detect free IL-4 in culture supernatants from cells stimulated with ASC in our system. Although this cytokine was not detected, we cannot rule out definitely the possibility that ASC induces the production of IL-4. It is possible that the cells need to be stimulated for longer periods to produce IL-4 at detectable levels in our culture system. Mosmann and Coffman (1989) examined the lymphokine profiles of helper clones from 2 to 6 weeks after establishment in culture, in some experiments, 
they could not detect a recognizable Th-1 or Th- 2 response at the early times, however, the cell clones sometimes changed into clear Th- 1 or Th- 2 phenotypes on continued growth in culture. They proposed a model in which a single precursor cell gives rise to either Th-1 or Th- 2 cells depending upon the antigen-presenting cell. The precursor cells synthesize a set of lymphokines that fit neither Th-1 or Th-2 patterns. In other words, memory $\mathrm{T}$ cells synthesize cytokines that fit a Th- 1 or Th-2 pattern and unprimed T cells synthesize cytokines at similar levels that do not necessarily fit any specific pattern.

Because results of IL-4 production by ASC-stimulated cultures was inconclusive, we decided to investigate a second Th- 1 type of cytokine in an attempt to establish a pattern of Th-1 response. We elected to assay for IFN- $\gamma$ in culture supernatants since this cytokine inhibits the proliferation of Th-2 cells, indicating that its presence will result in the preferential expansion of Th-1 cells during an immune response (De Maeyer and De Maeyer-Guignard, 1998; Gehring et al., 1998). Contrary to expectations, IFN- $\gamma$ could not be detected in ASC-stimulated culture supernatants after 48 hours of incubation. These negative results can be interpreted in three different ways: (1) ASC does not stimulate either IL-4 or IFN- $\gamma$ production by human PBMC, (2) there was not enough time provided under our experimental conditions for the cells to release these cytokines in the culture supernatants, and (3) background immunity of donors, which leads to the production of Th-1 or Th-2 clones preferably, depending on the antigenic stimulation and ongoing immune response at the time cells were collected. The investigation of the development of human $\mathrm{T}$ cell differentiation using freshly isolated cells, especially in its early phase, is not an easy task. It is not clear if polyclonal activation of naïve $\mathrm{T}$ cells by mitogens mimic physiological activation, which is triggered by HLA-TCR contact 
between the antigen-presenting cell and the T cell, in this system (Gehring et al., 1998). Cytokine profiles of helper clones in cultures are sometimes not recognizable Th- 1 or Th2 at early times (Mosmann and Coffman, 1989), however they can change into clear Th-1 or Th-2 phenotypes on continued growth in culture. In addition, there are reports of clones that secrete a mixture of the two patterns (Paliard et al., 1988; Maggi et al., 1988).

During this study, apoptosis in leukocytes stimulated with shark cartilage was assessed morphologically and by DNA fragmentation pattern. We found characteristic morphological changes indicative of apoptosis in leukocytes following incubation with shark cartilage. A statistically significant difference was not noted in the number of apoptotic cells present in cartilage-stimulated leukocyte preparations and those stimulated with $0.5 \mu \mathrm{M} / \mathrm{ml}$ of staurosporine, suggesting that shark cartilage induces apoptosis in human leukocytes. ASC did not induce apoptosis at a level obtained with higher concentrations of staurosporine. This result implies that the apoptosis inducer present in the ASC preparation could be in low concentrations. When cytospin monolayers from cultures containing apoptosis inducers or ASC was examined, they revealed apoptotic morphological changes more frequently present in mononuclear cells than in PMNs. PMns are terminal cells, therefore, they do not enter the cell cycle as mononuclear cells. As a result, the latter can be detected undergoing apoptosis more frequently.On the other hand, DNA fragmentation could not be demonstrated for either cartilage-stimulated cells or staurosporine-stimulated cells. Although oligonucleosomal cleavage accompanies apoptosis in most systems, it has been reported that apoptosis can occur in the absence of internucleosomal fragmentation (Oberhammer et al, 1993). The detection of the typical pattern of DNA ladder on agarose gel requires a large number of cells undergoing 
apoptosis to be visualized. Some protocols use $20 \times 10^{6}$ cells to be able to detect the typical ladder on the agarose gel (Wolfe et al, 1996). In our system we used $1.5 \times 10^{6}$ cells, which probably was not enough to show the typical DNA ladder. The induction of apoptosis on human leukocytes by ASC has an important relevance for cancer treatment. Apoptosis has been studied as an alternative for cancer treatment and prevention by controlling cell proliferation, which is a crucial process during tumor growth and development (Martin and Green, 1994; Mori et al., 1999). The induction of apoptosis by shark cartilage could justify its use in cancer treatment. Besides, TNF- $\alpha$ has been shown to induce apoptosis in some cell types, including endothelial cells (Polunovsky et al., 1994; Schwartz et al., 1999), which also could explain the use of shark cartilage for cancer treatment knowing that shark cartilage induces the production of TNF- $\alpha$.

During this study, we confirmed that a crude acid extract of shark cartilage stimulates TNF- $\alpha$ production in vitro by human leukocytes, as shown previously in our laboratory. We could not detect IL-4 or IFN- $\gamma$ in supernatants from cultures stimulated with shark cartilage, therefore, being unable to establish a Th-1 or Th-2 patter of cytokine response, detecting only one type of Th-1 cytokine. The production of IL-4 and IFN- $\gamma$ by shark cartilage-stimulated human leukocytes in vitro needs to be further studied in order to give a more definitive conclusion. We could also conclude that shark cartilage induced apoptosis in human leukocytes in vitro, in a similar fashion to $0.5 \mu \mathrm{M} / \mathrm{ml}$ of staurosporine. 


\section{References}

Abehsira-Amar O., Gibert M., Joliy M., Theze J. and Jankovic D.L. (1992). IL-4 plays a dominant role in the differential development of Th0 into Th1 and Th2 cells. The Journal of Immunology. 148: 3820-3829.

Angell M. and Kassirer J.P. (1998). Alternative medicine-the risks of untested and unregulated remedies. New England Journal of Medicine. 339: 839-841.

Arends M.J., Morris R.G. and Wyllie A.H. (1990). Apoptosis. The role of the endonuclease. American Journal of Pathology. 136: 593-608.

Baici A., Horler D., Moser B., Hofer H.O., Fehr K. and Wagenhauser F.J. (1992). Analysis of glycosaminoglycans in human serum after oral administration of chondroitin sulfate. Rheumatology International. 12: 81-88.

Banchereau J. and Rybak M.E. (1994). Interleukin-4. In: The cytokine handbook. Academic Press Inc., San Diego, California, pages 99-126.

Berbari P., Thibodeau A., Germain L., Saint-Cyr M., Gaudreau P., El-Khouri S., Dupont E. and Garrel D.R. (1999). Antiangiogenic effects of the oral administration of liquid cartilage extract in humans. Journal of Surgical Research. 87: 108-113.

Beyaert R. and Fiers W. (1998). Tumor necrosis factor and lymphotoxin. In: Cytokines. Academic Press Inc., San Diego, California, pages 335-360.

Blackadar C.B. (1993). Skeptics of oral administration of shark cartilage. Journal of the National Cancer Institute. 85: 1961-1962.

Brem H. and Folkman J. (1975). Inhibition of tumor angiogenesis mediated by cartilage. Journal of Experimental Medicine. 141: 427-439.

Campagno L.J.V. (1999). Conserving sharks. In: Sharks. Checkmark Books, New York, New York, pages 214-219.

Chen J., Chang C., Wu J. and Wang S. (2000). Shark cartilage extract interfers with cell adhesion and induces reorganization of focal adhesion in cultured endothelial cells. Journal of Cellular Biochemistry. 78: 417-428.

Davis P.F., He Y., Furneaux R.H., Johnston P.S., Ruger B.M. and Slim G.C. (1997). Inhibition of angiogenesis by oral ingestion of powdered shark cartilage in a rat model. Microvascular Research. 54: 178-182.

De Maeyer E. and De Maeyer-Guignard J. (1998). Interferon-Gamma. In: Cytokines. Academic Press Inc., San Diego, California, pages 335-360. 
Deal C.L. and Moskowitz R.W. (1999). Nutraceuticals as therapeutic agents in osteoarthritis. Rheumatic Disease Clinics of North America. 25: 379-395.

Dupont E., Savard P.E., Jourdain C., Juneau C., Thibodeau A., Ross N., Marenus K., Maes D.H., Pelletier G. and Sauder D.N. (1998). Antiangiogenic properties of a novel shark cartilage extract: Potential role in the treatment of psoriasis. Journal of Cutaneous Medicine and Surgery. 2: 146-152.

Durie B.G.M., Soehnlen B. and Prudden J.F. (1985). Antitumor activity of bovine cartilage extract (Catrix-S) in the human tumor stem cell assay. Journal of Biological Response Modifiers. 4: 590-595.

Eisenberg D.M., Davis R.B., Ettner S.L., Appel S., Wilkey S., Rompay M.V. and Kessler R.C. (1998). Trends in alternative medicine use in the United States, 1990-1997. The Journal of the American Medical Association. 280: 1569-1575.

Eisenberg D.M., Kessler R.C., Foster C., Norlock F.E., Calkins D.R. and Delbanco T.L. (1993). Unconventional medicine in the United States. New England Journal of Medicine. 328: 246-252.

Ernst E. (1998). Shark cartilage for cancer? The Lancet. 351: 298.

Ernst E. and Cassileth B.R. (1999). How useful are unconventional cancer treatments? European Journal of Cancer. 35: 1608-1613.

Feldmann M. and Maini R.N. (1999). The role of cytokines in the pathogenesis of rheumatoid arthritis. Rheumatology. 38: 3-7.

Felzenszwalb I., Pelielo de Mattos J.C., Bernardo-Filho M. and Caldeira de Araujo A. (1998). Shark cartilage-containing preparation: protection against reactive oxygen species. Food and Chemical Toxicology. 36: 1079-1084.

Folkman J. (1971). Tumor angiogenesis: therapeutic implications. New England Journal of Medicine. 285: 1182-1186.

Fontenele J.B., Araujo G.B., De Alencar J.W. and Viana G.S. (1997). The analgesic and anti-inflammatory effects of shark cartilage are due to a peptide molecule and are nitric oxide (NO) system dependent. Biological and Pharmaceutical Bulletin. 20: 1151-1154.

Fontenele J.B., Viana G.S., Xavier-Filho J. and De Alencar J.W. (1996). Antiinflammatory and analgesic activity of a water-soluble fraction from shark cartilage. Brazilian Journal of Medical and Biological Research. 29: 643-646.

Gajewski T.F., Schell S.R., Nau G. and Fitch F.W. (1989). Regulation of T-cell activation: differences among T-cell subsets. Immunological Reviews. 111: 79-110. 
Gardner M.L.G. (1988). Gastrointestinal absorption of intact proteins. Annual Review of Nutrition. 8: 329-350.

Gehring S., Schlaak M. and van der Bosch J. (1998). A new in vitro model for studying human $\mathrm{T}$ cell differentiation: $\mathrm{T}_{\mathrm{h} 1} / \mathrm{T}_{\mathrm{h} 2}$ induction following activation by superantigens. Journal of Immunological Methods. 219: 85-98.

Gomes E.M., Souto P.R. and Felzenszwalb I. (1996). Shark-cartilage containing preparation protects cells against hydrogen peroxide induced damage and mutagenesis. Mutation Research. 367: 204-208.

Gordon J.S. (1996). Alternative medicine and the family physician. American Family Physician. 54: 2205-12.

Griffioen A.W. and Molema G. (2000). Angiogenesis: potentials for pharmacologic intervention in the treatment of cancer, cardiovascular diseases, and chronic inflammation. Pharmacological Reviews. 52: 237-268.

Griffioen A.W., Barendsz-Janson A.F., Mayo K.H. and Hillen H.F.P. (1998). Angiogenesis, a target for tumor therapy. Journal of Laboratory and Clinical Medicine. 132: $363-368$.

Henderson C.J. and Panush R.S. (1999). Diets, dietary supplements, and nutritional therapies in rheumatic diseases. Rheumatic Disease Clinics of North America. 25: 937968.

Hynes R.O. (1992). Integrins: versatility, modulation, and signaling in cell adhesion. Cell. 69: 11-25.

Jackson J.R., Seed M.P., Kircher C.H., Willoughby D.A. and Winkler J.D. (1997). The codependence of angiogenesis and chronic inflammation. The FASEB Journal. 11: 457465 .

Langer R., Brem H., Falterman K., Klein M and Folkman J. (1976). Isolation of a cartilage factor that inhibits tumor neovascularization. Science. 193: 70-2.

Lee A. and Langer R. (1983). Shark cartilage contains inhibitors to tumor angiogenesis. Science. 221: 1185-1187.

Lundberg A.S. and Weinberg R.A. (1999). Control of the cell cycle and apoptosis. European Journal of Cancer. 35: 1886-1894.

Maggi E., Del Prete G., Macchia D., Parronchi P., Tiri A., Chretien I., Ricci M. and Romagnani S. (1988). Profiles of lymphokine activities and helper function for $\operatorname{IgE}$ in human T cell clones. European Journal of Immunology. 18: 1045-1050. 
Marcus C.L. (1999). Alternative Medicine-The AMA reviews scientific evidence. Clinician reviews. 9: 87-90.

Markman M. (1996). Shark cartilage: the laetrile of the 1990s. Cleveland Clinic. Journal of Medicine. 63: 179-80.

Martin S.J. and Green D. (1994). Apoptosis as goal of cancer therapy. Current Opinion in Oncology. 6:616-621.

Mathews J. (1992). Sharks still intrigue cancer researchers. Journal of the National Cancer Institute. 84: 1000-1001.

Mathews J. (1993). Media feeds frenzy over shark cartilage as cancer treatment. Journal of the National Cancer Institute. 85: 1190-1191.

McGuire T.R., Kazakoff P.H., Hoie E.B. and Fienhold M.A. (1996). Antiproliferative activity of shark cartilage with and without tumor necrosis factor- $\alpha$ in human umbilical vein endothelium. Pharmacotherapy. 16:237-244.

Miller D.R., Anderson G.T., Stark J.J., Granick J.L. and Richardson D. (1998). Phase I/II trial of the safety and efficacy of shark cartilage in the treatment of advanced cancer. Journal of Clinical Oncology. 16: 3649-3655.

Mori H., Sugie S., Yoshimi N., Hara A. and Tanaka T. (1999). Control of cell proliferation in cancer prevention. Mutation Research. 428: 291-298.

Morris G.M., Coderre J.A., Micca P.L., Lombardo D.T. and Hopewell J.W. (2000). Boron neutron capture therapy of the rat 9L gliosarcoma: evaluation of the effects of shark cartilage. The British Journal of Radiology. 73: 429-434.

Moses M.A., Sudhalter J. And Langer R. (1990). Identification of an inhibitor of neovascularization from cartilage. Science. 248: 1408-1410.

Mosmann T.R. and Coffman R.L. (1989). TH1 and TH2 cells: different patterns of lymphokine secretion lead to different functional properties. Annual Reviews in Immunology. 7: 145-173.

Muscat M. (1999). National cancer institute's OCCAM partners with NCCAM to expand research on unconventional cancer treatments. Alternative Therapies. 5: 26-30.

Oberhammer F., Wilson J.W., Dive C., Morris I.D., Hickman J.A., Wakeling A.E., Walker P.R. and Sikorska M. (1993). Apoptotic death in epithelial cells: cleavage of DNA to 300 and/or $50 \mathrm{~kb}$ fragments prior to or in the absence of internucleosomal fragmentation. The European Molecular Biology Organization Journal. 12:3679-3684.

Oikawa T., Ashino-Fuse H., Shimamura M., Koide U. and Iwaguchi T. (1990). A novel angiogenic inhibitor derived from japanese shark cartilage (I). Extraction and estimation 
of inhibitory activities toward tumor and embryonic angiogenesis. Cancer Letters. 51:181-186.

Olsen A.M. (1999). Using sharks. In: Sharks. Checkmark Books, New York, New York, pages 206-213.

Paliard X., de Waal Malefijt R., Yssel H., Blanchard D., Chretien I., Abrams J., de Vries $\mathrm{J}$ and Spits H. (1988). Simultaneous production of IL-2, IL-4 and IFN-gamma by activated human CD4+ and CD8+ T cells clones. Journal of Immunology. 141: 849-855.

Pettit G.R. and Ode R.H. (1977). Antineoplastic agents L: isolation and characterization of sphyrnastatins 1 and 2 from the hammerhead shark Sphyrna lewini. Journal of Pharmaceutical Sciences. 66: 757-758.

Polunovsky V.A., Wendt C.H., Ingbar D.H., Peterson M.S. and Bitterman P.B. (1994). Induction of endothelial cell apoptosis by TNF alpha: modulation by inhibitors of protein synthesis. Experimental Cellular Research. 214: 584-594.

Prieur D.J., Fenstermacher J. D. and Guarino A.M. (1976). A choroids plexus papilloma in an elasmobranch (Squalus acanthias). Journal of the National Cancer Institute. 56: 1207-1208.

Prudden J.F. (1985). The treatment of human cancer with agents prepared from bovine cartilage. Journal of Biological Response Modifiers. 4: 551-584.

Redmond H.P., Schuchter L., Bartlett D., Kelly C.J., Shou J., Leon P. and Daly J.M. (1992). Anti-neoplastic effects of interleukin-4. Journal of Surgical Research. 52: 406411.

Romano C.F., Lipton A., Harvey H.A., Simmonds M.A., Romano P.J. and Imboden S.L. (1985). A phase II study of catrix-S in solid tumors. Journal of Biological Response Modifiers. 4: 585-589.

Rosen J., Sherman W.T., Prudden J.F. and Thorbecke G.J. (1988). Immunoregulatory effects of Catrix. Journal of Biological Response Modifiers. 7:498-512.

Saraste A. and Pulkki K. (2000). Morphologic and biochemical hallmarks of apoptosis. Cardiovascular Research. 45: 528-537.

Schwartz B.R., Karsan A., Bombeli T. and Harlan J.M. (1999). A novel $\beta 1$ integrindependent mechanism of leukocyte adherence to apoptotic cells. The Journal of Immunology. 162: 4842-4848.

Sheu J.R., Fu C.C., Tsai M.L. and Chung W.J. (1998). Effect of U-995, a potent shark cartilage-derived angiogenesis inhibitor, on anti-angiogenesis and anti-tumor activities. Anticancer Research. 18: 4435-4442. 
Sidhu R.S. and Bollon A.P. (1993). Tumor necrosis factor activities and cancer therapy-A perspective. Pharmacology and Therapeutics. 57: 79-128.

Simjee S.U. (1997). Secretion of tumor necrosis factor by human leukocytes stimulated with shark cartilage. Master Thesis, Florida International University.

Simjee S.U. and Smith S.L. (1997). Stimulated secretion of TNF- $\alpha$ by human leukocytes. Developmental and Comparative Immunollogy. 21:(k8) 170.

Simone C.B., Simone N.L. and Simone II C.B. (1998). Shark cartilage for cancer. The Lancet. 351: 1440.

Simpfendorfer C. (1998). Shark behavior. In: Reader's digest explorers. Sharks. The Reader's Digest Association, Inc., Pleasantville, New York, pages 76-83.

Storgard C.M., Stupack D.G., Jonczyk A., Goodman S.L., Fox R.I. and Cheresh D.A. (1999). Decreased angiogenesis and arthritic disease in rabbits treated with an $\alpha v \beta 3$ antagonist. The Journal of Clinical Investigation. 103:47-54.

Street N.E. and Mosmann T.R. (1991). Functional diversity of T lymphocytes due to secretion of different cytokine patterns. FASEB Journal. 5: 171-177.

Swain S.L., Bradley L.M., Croft M., Tonkonogy S., Atkins G., Weiberg A.D., Duncan D.D., Hedrick S.M., Dutton R.W. and Huston G. (1991). Helper T-cell subsets: phenotype, function and the role of lymphokines in regulating their development. Immunollogical Reviews. 123: 115-142.

Tomei L.D. and Cope F.O. (1991). Apoptosis: the molecular basis of cell death. Current communications in cell \& molecular biology; 3. Cold Spring Harbor Laboratory Press, Plainview, New York.

Tracey K.J. (1994). Tumour Necrosis Factor-Alpha. In: The cytokine handbook. Academic Press Inc., San Diego, California, pages 289-318.

Tricas T.C. (1999). Shark ecology. In: Sharks. Checkmark Books, New York, New York, pages 96-103.

Volpi N. (1996). Physico-chemical properties and the structure of dermatan sulfate fractions purified from plasma after oral administration in healthy human volunteers. Thrombosis and Haemostasis. 75: 491-496.

Warshaw A.L., Walker W.A. and Isselbacher K.J. (1974). Protein uptake by the intestine: evidence for absorption of intact macromolecules. Gastroenterology. 66: 987-992.

Wolfe J.T., Pringle J.H. and Cohen G.M. In: Techniques in apoptosis. A user's guide. Portland Pres, London, U.K., pages 53-69. 
Workshop on alternative medicine. Washington, DC: US Government Printing Office, 1992. 


\section{Appendix i}

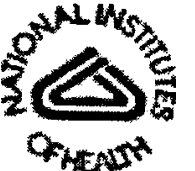

FOR CONSUMERS AND PRACTITIONERS

NATIONAL CENTER FOR COMPLEMENTARY \& ALTERNATIVE MEDICINE

$M$ ajor Domains of Complementary \& Alternative Medicine

Complementary and alternative healthcare and medical practices (CAM) are those healthcare and medical practices that are not currently an integral part of conventional medicine 1 . The list of practices that are considered CAM changes continually as CAM practices and therapies that are proven safe and effective become accepted as "mainstream" healthcare practices. Today, CAM practices may be grouped within five major domains 2 : (1) alternative medical systems, (2) mind-body interventions, (3) biologically-based treatments, (4) manipulative and body-based methods, and (5) energy therapies. The individual systems and treatments comprising these categories are too numerous to list in this document. Thus, only limited examples are provided within each.

\section{ALTERNATIVE MEDICAL SYSTEMS}

Alternative medical systems involve complete systems of theory and practice that have evolved independent of and often prior to the conventional biomedical approach. Many are traditional systems of medicine that are practiced by individual cultures throughout the world, including a number of venerable Asian approaches.

Traditional oriental medicine emphasizes the proper balance or disturbances of qi (pronounced chi), or vital energy, in health and disease, respectively. Traditional oriental medicine consists of a group of techniques and methods, including acupuncture, herbal medicine, oriental massage, and qi gong (a form of energy therapy described more fully below). Acupuncture involves stimulating specific anatomic points in the body for therapeutic purposes, usually by puncturing the skin with a needle.

Ayurveda is India's traditional system of medicine. Ayurvedic medicine (meaning "science of life") is a comprehensive system of medicine that places equal emphasis on body, mind, and spirit, and strives to restore the innate harmony of the individual. Some of the primary Ayurvedic treatments include diet, exercise, meditation, herbs, massage, exposure to sunlight, and controlled breathing.

Other traditional medical systems have been developed by Native American, Aboriginal, African, Middle-Eastern, Tibetan, Central and South American cultures.

Homeopathy and naturopathy are also examples of complete alternative medical systems. Homeopathy is an unconventional Western system that is based on the principle that "like cures like," i.e., that the same substance that in large doses produces the symptoms of an illness, in very minute doses cures it. Homeopathic physicians believe that the more dilute the remedy, the greater its potency. Therefore, homeopaths use small doses of specially prepared plant extracts and minerals to stimulate the body's 
defense mechanisms and healing processes in order to treat illness.

Naturopathy views disease as a manifestation of alterations in the processes by which the body naturally heals itself and emphasizes health restoration rather than disease treatment. Naturopathic physicians employ an array of healing practices, including diet and clinical nutrition; homeopathy; acupuncture; herbal medicine; hydrotherapy (the use of water in a range of temperatures and methods of applications); spinal and soft-tissue manipulation; physical therapies involving electric currents, ultrasound, and light therapy; therapeutic counseling; and pharmacology.

\section{MIND-BODY INTERVENTIONS}

Mind-body interventions employ a variety of techniques designed to facilitate the mind's capacity to affect bodily function and symptoms. Only a subset of mind-body interventions are considered CAM. Many that have a well-documented theoretical basis, for example, patient education and cognitive-behavioral approaches are now considered "mainstream." On the other hand, meditation, certain uses of hypnosis, dance, music, and art therapy, and prayer and mental healing are categorized as complementary and alternative.

\section{BIOLOGICAL-BASED THERAPIES}

This category of CAM includes natural and biologically-based practices, interventions, and products, many of which overlap with conventional medicine's use of dietary supplements. Included are herbal, special dietary, orthomolecular, and individual biological therapies.

Herbal therapies employ individual or mixtures of herbs for therapeutic value. An herb is a plant or plant part that produces and contains chemical substances that act upon the body. Special diet therapies, such as those proposed by Drs. Atkins, Ornish, Pritikin, and Weil, are believed to prevent and or control illness as well as promote health. Orthomolecular therapies aim to treat disease with varying concentrations of chemicals, such as, magnesium, melatonin, and mega-doses of vitamins. Biological therapies include, for example, the use of laetrile and shark cartilage to treat cancer and bee pollen to treat autoimmune and inflammatory diseases.

\section{MANIPULATIVE AND BODY-BASED METHODS}

This category includes methods that are based on manipulation and/or movement of the body. For example, chiropractors focus on the relationship between structure (primarily the spine) and function, and how that relationship affects the preservation and restoration of health, using manipulative therapy as an integral treatment tool. Some osteopaths, who place particular emphasis on the musculoskelatal system, believing that all of the body's systems work together and that disturbances in one system may have an impact upon function elsewhere in the body, practice osteopathic manipulation. Massage therapists manipulate the soft tissues of the body to normalize those tissues. 


\section{ENERGY THERAPIES}

Energy therapies focus either on energy fields originating within the body (biofields) or those from other sources (electromagnetic fields).

Biofield therapies are intended to affect the energy fields, whose existence is not yet experimentally proven, that surround and penetrate the human body. Some forms of energy therapy manipulate biofields by applying pressure and/or manipulating the body by placing the hands in, or through, these fields. Examples include Qi gong, Reiki and Therapeutic Touch. Qi gong is a component of traditional oriental medicine that combines movement, meditation, and regulation of breathing to enhance the flow of vital energy (qi) in the body, to improve blood circulation, and to enhance immune function. Reiki, the Japanese word representing Universal Life Energy, is based on the belief that by channeling spiritual energy through the practitioner the spirit is healed, and it in turn heals the physical body. Therapeutic Touch is derived from the ancient technique of "laying-on of hands" and is based on the premise that it is the healing force of the therapist that affects the patient's recovery and that healing is promoted when the body's energies are in balance. By passing their hands over the patient, these healers identify energy imbalances.

Bioelectromagnetic-based therapies involve the unconventional use of electromagnetic fields, such as pulsed fields, magnetic fields, or alternating current or direct current fields, to, for example, treat asthma or cancer, or manage pain and migraine headaches.

1 The term conventional medicine refers to medicine as practiced by holders of M.D. (medical doctor) or D.O. (doctor of osteopathy) degrees, some of whom may also practice complementary and alternative medicine. Other terms for conventional medicine are allopathy, Western, regular, and mainstream medicine, and biomedicine. [ Return to CAM Domains ]

2 These are the categories within which NCCAM has chosen to group the numerous CAM practices; others employ different, broad groupings. [ Return to CAM Domains ]

NCCAM Home / Consumers \& Practitioners

Menu...

Please send questions and comments to nccam-info@nccam.nih.gov.

Last Updated: September 14, 2000 
So far, over 550 patients have been given the drug in clinical studies in Canada and the United States, some of them for more than 3 years. These studies indicate that $F-941$ has a good safety and tolerability profile, both alone and in combination with chemotherapy and radiotherapy treatments.

\section{Oncology (E-941/Neovastat)}

After having completed a Phase I/II trial in lung and prostate cancer, and a Phase I trial in breast cancer during 1999, as scheduled, Fterna has received approval from the Health Protection branch (HPB) in Canada, and the Food and Drug Administration (FDA) in the United States to begin a Phase III trial of $/ E$ $941 /$ Neovastat in lung cancer patients.

This trial is sponsored by the U.S. National Cancer Institute (NCI) and will focus on the use of $F E-941 /$ Neovastat together with chemotherapy and radiotherapy to treat lung cancer. It will be a double-blind placebo-controlled study involving approximately 800 patients with non-operable non-small-cell lung cancer. The patients will be administered standard chemotherapy and radiotherapy and randomized in two groups. One group will be administered Neovastat and the other a placebo. The primary endpoint will be survival. The study will involve over 60 hospitals and cancer centers in the U.S. and Canada. Recruitment will be coordinated through the Community Cooperative Oncology Program (CCOP) of the MD Anderson Cancer Center.

Applications to begin another Phase MI trial of $E-941 /$ Neovastat have also been filed for the treatment of patients with progressive renal cell carcinoma. Renal cell carcinoma is the most common type of kidney cancer in adults which affects approximately 34,000 people a year in North America. At the moment, there are few therapies available for RCC. These therapies have serious side effects and only a small number of patients treated respond to the therapy.

This trial is expected to begin in North America and Europe shortly after receiving approval from the HPB and the FDA and will take place in about 40 investigative sites involving approximately 270 patients.

Clinical data summary. Over 450 patients have been exposed to the drug and some with an exposure of more than three years. The optimum dose to perform pivotal studies was determined without limitations due to toxicity.

\section{Study details.}

\section{Breast, lung or prostate cancer, Phase I/II}

This study was a multi-center, open-label, dose-ranging study for the evaluation of the safety, tolerability and efficacy of Neovastat. The compound was administered orally for 12 weeks in patients with solid tumors of the breast, lung or prostate that were refractory to standard therapies, or for whom there were no standard therapies available.

The objectives of the study were to assess the safety and tolerability of Neovastat at four different doses in these patients, and to obtain preliminary information on the efficacy of Neovastat in order to select the dose for Phase 
Breast cancer cohort. The Phase I of the breast cancer cohort was closed in June 1998. Because many other treatments currently approved or under investigation are also accessible to that patient population, it was decided in June 1998 not to proceed with Phase II of the breast cancer cohort.

Lung cancer cohort. A total of 43 patients were recruited from December 1996 to October 1997. An interim analysis was performed at the end of Phase I to determine the dose to be administered during Phase II of the study. A positive dose response was established during interim analysis, in favor of the highest dose. The clinical index score was improved by more than $50 \%$ at the highest dose compared to the lowest dose. The absence of significant toxicity and the preliminary efficacy data prompted the choice of the highest dose ( 240 $\mathrm{mL} /$ day) as the optimal dose for the Phase II of the study.

A total of 37 additional patients were recruited from January 1998 to June 1998, with 21 patients completing 84 days of treatment at a dose of 240 $\mathrm{mL} /$ day.

Results from a retrospective analysis of the lung cancer cohort suggested that the higher doses ( $240 \mathrm{~mL}$ per day) of Neovastat significantly increased the median survival time by $47 \%$, as compared to lower doses in patients with refractory non-small-cell lung cancer (locally recurrent or metastatic). The data also confirmed the appropriateness of the dose which will be used in a randomized double-blind placebo-controlled Phase III trial to be started shortly.

Prostate cancer cohort. A total of 34 patients were recruited from March 1997 to March 1998. Of those, a total of 22 patients completed 84 days of treatment. An interim analysis was performed at the end of Phase I to determine the dose to be administered in Phase II of the study. Similar to the observations in the lung cancer cohort, oral administration of Neovastat resulted in a favorable safety profile, and showed a positive trend in favor of a dose-related therapeutic benefit.

A total of 38 additional patients were recruited from June 1998 to October 1998 , with 20 patients completing 84 days of treatment at a dose of 240 $\mathrm{ml} /$ day. Results will be presented shortly.

\section{Special access program}

The special access program allows physicians to request drugs not approved in Canada in order to treat patients suffering from serious or life threatening itir:sunes wriele standard therapies have failed or are unsuitable. The safety and efficacy parameters in this study are similar to those listed above.

The dose of Neovastat used in this program was $60 \mathrm{~mL} /$ day as an open-ended treatment. Over 100 physicians have presented such a request to the SAP for patients with different types of solid tumors. The program started in August 1996 and ended in June 1997 after including 150 patients. Based on data from the lung cancer patient cohort and the prostate cancer patient cohort described in the above study, all cancer patients participating in this trial had their dose 
increased to $240 \mathrm{~mL} /$ day. As of Jurie 1999 eight patients were still receiving Neovastat. Some of the patients in the study received chemotherapy in combination with Necvastat.

\section{Refractory solid tumors Phase I}

The clinical trial using Neovastat for the treatment of refractory solid tumors in combination with currently available treatments is still ongoing but the recruitment is completed. In this trial, Neovastat is administered daily at oral doses of $240 \mathrm{ml} /$ day. The objective of this clinical trial is to evaluate the long term safety of Neovastat in combination or monotherapy in the treatment of refractory solid tumors.

\section{Dermatology}

Eterna's focus is moderate to severe plaque psoriasis. The convenience of oral administration and low toxicity associated with $Æ$-941/Neovastat are essential for patients who will be taking this medication over long periods. A randomized, dose-ranging Phase I/II monotherapy trial for $F E-941 /$ Neovastat has been completed.

Clinical data summary. Results from a Phase I/II clinical trial outlined $\mathbb{E \text { - }}$ $941 /$ Neovastat's safety and tolerability, and indicated preliminary signs of efficacy. No serious adverse side effects were identified at any dosage level during the first three months of the trial. A total of 30 patients were evaluated. These results revealed that $\mathscr{F}$-941/Neovastat had a positive statistically significant effect on the condition of patients suffering from psoriasis with regards to the PASI score (Psoriasis Area and Severity Index). The PASI score of the patients treated showed a dose-response effect, with patients having received the highest dose showing the greatest improvement in PASI score. In addition, in self-assessment evaluations, $70 \%$ of patients having completed the 12 weeks of treatment stated that their condition had improved with the administration of Æ-941/Neovastat.

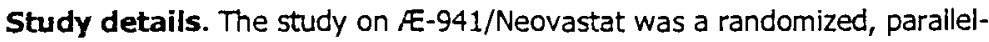
arm, dose-comparison study for the evaluation of the safety, tolerability and efficacy of $\digamma E-941 /$ Neovastat administered oraily for 12 weeks in patients with moderate to severe psoriasis. A total of 49 patients were recruited for the trial, with patient enroilment starting in January 1998 and ending in July 1998. Patients were given between $30 \mathrm{~mL}$ and $240 \mathrm{~mL} /$ day for 12 weeks, foliowed by a 12-week period without treatment. The primary end point of efficacy was based primarily on the PASI (Psoriasis Area and Severity Index) scoring system at pre-determined intervals during the trial. $Æ-941 /$ Neovastat showed a positive dose dependent effect, with patients receiving the highest dose compared to the lowest dose showing statistically significant improvement in PASI score. EE-941/Neovastat was well tolerated at all doses tested and no serious adverse events were reported during the study.

\section{Ophthalmology}

The main target in ophthaimoiogy is age-related macular degeneration. The objectives of the Phase I monotherapy trial were to determine the safety and 
tolerability of $\&-941 /$ Neovastat and the most effective dosage for further clinical trials. This study was a single-center Canadian study involving 10 patients. The results of this study, presented in December 1999, established the safety and tolerability of the compound and provided evidence of a doseresponse effect.

Study details. A dose titration study was conducted to evaluate the safety, tolerability and efficacy of $E-941 /$ Neovastat which was administered orally for 30 weeks in age-related macular degeneration patients for whom no standard therapies were available. The objectives of the study were to assess the safety and tolerability of $F-941 /$ Neovastat in these patients, and to evaluate the effects of $/ E-941 /$ Neovastat on progression of neovascularization in the eye and its impact on the visual acuity in such patients. Each patient was initially treated with a dose of $30 \mathrm{~mL} /$ day for six weeks. Based on response, the dose was doubled gradually every six weeks up to $240 \mathrm{~mL} /$ day.

Last update 02/17/00 


\section{Appendix iii}

\section{INFORMED CONSENT \\ STUDY OF THE BIOACTIVITY OF SHARK CARTILAGE}

I freely and voluntarily consent to be a blood donor in the research project entitled Study of the Bioactivity of Shark Cartilage to be conducted at Florida International University (University Park campus) during the Summer, Fall and Spring Semesters, 1999-2000, with Sylvia L. Smith as Principal Investigator. I have been told that this procedure will last approximately five (5) minutes.

$I$ understand that the purpose of this research is to examine the effect of shark cartilage extracts on various functional parameters of human peripheral blood leukocytes.

I understand that the research procedure will involve donating approximately $25 \mathrm{ml}$ (no more than $30 \mathrm{ml}$ ) of blood on a bi-weekly basis for the purpose of isolating blood leukocytes to set up in vitro cell cultures. Blood will be obtained by venipuncture and drawn by a person licensed to perform phlebotomy by the State of Florida. The procedure will be as follows: a tourniquet will be applied to the upper arm to increase stasis and the phlebotomist might use the tip of the index finger to palpate the vein (median cubital, cephalic or basilic vein), after cleansing the area of skin at the bend of the elbow with a $70 \%$ isopropyl alcohol swab, the phlebotomist, using the appropriate fine gauge needle, will puncture the skin and insert the needle into the vein. The experience will feel like a pin prick or that of an injection. Blood will be gently withdrawn into the appropriate collecting tubes. The toumiquet will be released before the needle is withdrawn from the arm and immediately pressure will be applied to the site of the puncture wound. A very small amount of blood (less than a drop) may flow after removal of the needle. The area will be cleansed and a protective band aid applied.

I understand that there are no known benefits involved in my participation in this experiment. However, I understand that the following risks may be involved in my participation in this experiment. Occasionally, volunteers experience a slight dizziness, mild nausea, or fainting spell. On rare occasions the procedure might result in the formation of a hematoma at the site of puncture, which usually resolves naturally within a week. I understand that no compensation is available from Florida International University or any of its agents should some injury occur. I have been told there will be up to four (4) volunteer blood donors in this study.

I understand that I may withdraw my consent and discontinue participation in this research project at any time with no negative consequences. I have been given the right to ask questions concerning the procedure, and any questions have been answered to my satisfaction.

I understand that if I desire further information about this research I should contact Sylvia L. Smith at 305-348-3183. I have been offered a copy of this informed consent form.

I have read and understand the above.

Participant's signature

Date

I have explained and defined in detail the research procedure in which the participant has agreed to participate, and I have offered him/her a copy of this informed consent form. 


\section{Appendix iv}

Reagents and Chemicals

Supplier

Bio-Rad

161-0716

Tris

161-0301

SDS

Life Technologies

22400-089

10082-139

13139

15140-122

15581-044

15558-042

15585-011

15612-013
RPMI-1640 w/ HEPES

Fetal bovine serum

PMA

Penicillin-Streptomycin

TBE

TAE

Ethidium bromide

Hind III DNA fragments

Fisher Scientific

A507-500

S271-500

A142-212

22122-911
Acedic acid, glacial

Sodium chloride, crystal

Hydrochloric acid

Hema 3 staining system 
Sigma

$\begin{array}{ll}\text { A0169 } & \text { Agarose, Type 1-A } \\ \text { D-8779 } & \text { Dimethyl sulfoxide (DMSO) } \\ \text { T8154 } & \text { Trypan Blue } \\ \text { M2128 } & \text { MTT } \\ \text { 210-50 } & \text { E-Toxate kit } \\ \text { H3149 } & \text { Heparin } \\ \text { D5251 } & \text { Dextran (MW 500,000) } \\ \text { H1077-1 } & \text { Histopaque-1077 } \\ \text { T4428 } & \text { Toluene } \\ \text { S4400 } & \text { Staurosporine } \\ \text { C9911 } & \text { Camptothecin } \\ \text { C5275 } & \text { ConA } \\ \text { L6386 } & \text { LPS }\end{array}$

Endogen Inc

EH2-TNFA

EH2-IL4

EH-IFNG

Solgar Laboratories
Human TNF- $\alpha$ ELISA kit

Human IL-4 ELISA kit

Human IFN- $\gamma$ ELISA kit

Shark cartilage 
Supplier

Pierce

23225

Roche Diagnostics
Item

BCA protein assay kit

DNA ladder kit 